\title{
Acute and Chronic Dopamine Receptor Stimulation Modulates AMPA Receptor Trafficking in Nucleus Accumbens Neurons Cocultured with Prefrontal Cortex Neurons
}

\author{
Xiu Sun, Michael Milovanovic, Yun Zhao, and Marina E. Wolf \\ Department of Neuroscience, Rosalind Franklin University of Medicine and Science, North Chicago, Illinois 60064
}

\begin{abstract}
Postsynaptic interactions between dopamine (DA) and glutamate receptors in the nucleus accumbens (NAc) are critical for addiction. To determine the effect of acute and repeated DA receptor stimulation on AMPA receptor (AMPAR) synaptic targeting in medium spiny NAc neurons, we developed a model system consisting of rat NAc neurons cocultured with prefrontal cortex neurons from enhanced green fluorescent protein-expressing mice. Cortical neurons restore excitatory input onto NAc neurons but are distinguishable based on fluorescence. First, we showed that brief $\mathrm{D}_{1}$-like agonist exposure increased AMPAR insertion onto extrasynaptic regions of NAc neuronal processes through a mechanism requiring protein kinase $\mathrm{A}$. This facilitated the $\mathrm{Ca}^{2+} /$ calmodulin dependent protein kinase II (CaMKII)-dependent synaptic incorporation of AMPARs in response to subsequent NMDA receptor (NMDAR) stimulation. Through this mechanism, DA may promote reward-and drug-related plasticity in the NAc. Then, to model effects of repeated in vivo cocaine exposure, we treated cocultures with DA $(1 \mu \mathrm{M}, 30 \mathrm{~min})$ on days 7,9 , and 11 in culture. On day 15, NAc neurons exhibited increased synaptic AMPAR levels. This was associated with CaMKII activation and was blocked by the CaMKII inhibitor KN-93 ( $N$-[2-[ $N$-(4-chlorocinnamyl)- $N$ methylaminomethyl]phenyl]-N-(2-hydroxyethyl)-4-methoxybenzenesulfonamide phosphate salt). Furthermore, $\mathrm{D}_{1}$-like agonist exposure on day 15 no longer increased AMPAR surface expression. This refractoriness was associated with decreased $\mathrm{D}_{1}$ receptor surface expression. NMDAR surface expression was not altered by acute or repeated DA receptor stimulation. These results suggest that (1) after repeated DA treatment, NAc neurons are more responsive to glutamate inputs but $\mathrm{D}_{1}$-like receptor regulation of plasticity is impaired, and (2) NAc/prefrontal cortex cocultures are useful for studying dopamine-induced neuroadaptations.
\end{abstract}

Key words: $\mathrm{D}_{1}$ receptor; CaMKII; GluR1; LTP; plasticity; protein kinase A

\section{Introduction}

Repeated exposure to psychomotor stimulants can produce persistent changes in drug-seeking behavior in rodents that resemble those associated with human addiction (Deroche-Gamonet et al., 2004; Vanderschuren and Everitt, 2004; Bossert et al., 2005). This appears to involve glutamate-dependent plasticity in neuronal circuits that mediate drug seeking and craving (Wolf et al., 2004; Kauer and Malenka, 2007). The goal of this study was to investigate the effects of acute and chronic dopamine (DA) receptor stimulation on synaptic trafficking of AMPA receptors (AMPARs) in neurons of the rat nucleus accumbens (NAc). Activitydependent regulation of AMPAR levels in excitatory synapses is a

Received Jan. 29, 2007; revised March 10, 2008; accepted March 12, 2008.

This work was supported by National Institute on Drug Abuse Grants DA015835 and DA00453 (M.E.W.). We thank Dr. Marjorie Ariano for providing DA receptor antibodies, Dr. Amy Boudreau for conducting experiments on PKA substrate antibody specificity, Drs. Carrie Ferrario and Can Gao for helpful comments on this manuscript, and Dr. Stephen Rayport for suggesting the use of EGFP mice in cocultures many years ago.

Correspondence should be addressed to Marina E. Wolf, Department of Neuroscience, Rosalind Franklin University of Medicine and Science, 3333 Green Bay Road, North Chicago, IL 60064. E-mail: marina.wolf@rosalindfranklin.edu.

DOI:10.1523/JNEUROSCI.0258-08.2008

Copyright $\odot 2008$ Society for Neuroscience $\quad 0270-6474 / 08 / 284216-15 \$ 15.00 / 0$ critical mechanism for changing synaptic strength during longterm potentiation (LTP), long-term depression, and synaptic scaling (Malinow and Malenka, 2002; Turrigiano and Nelson, 2004).

The NAc plays a central role in neuronal circuits that mediate motivated behaviors related to natural rewards and drugs of abuse (Kelley, 2004). Neurons in the NAc consist of two major classes: GABAergic medium spiny neurons (90\%), the projection neurons of the NAc, and at least four populations of interneurons (10\%) (Meredith and Totterdell, 1999). The importance of medium spiny neurons in generating motivated behaviors reflects their role as an interface between limbic and motor systems. Medium spiny neurons receive inputs related to motivational state from DA neurons originating in the ventral mesencephalon and from glutamate neurons originating in the prefrontal cortex (PFC) and limbic regions such as the hippocampus and amygdala. They send projections to the ventral pallidum and ventral mesencephalon, regions involved in motor execution of motivated behaviors (Mogenson et al., 1987; Groenewegen et al., 1999; Kelley, 1999).

DA and glutamate inputs converge on common spines of medium spiny neurons (Jay, 2003; Sesack et al., 2003), and postsyn- 
aptic interactions between these transmitter systems are critical for the effects of psychomotor stimulants (Wolf, 1998; Schmidt et al., 2005). We have conducted a series of studies to test the hypothesis that DA receptors, by activating signaling pathways that modulate AMPAR trafficking, influence plasticity at adjacent glutamate synapses on medium spiny neurons. Using postnatal NAc cultures, we found that brief incubation with a $\mathrm{D}_{1}$-like agonist increased phosphorylation of the AMPAR subunit glutamate receptor subtype 1 (GluR1) at the protein kinase A (PKA) site (Chao et al., 2002a) and also increased GluR1 insertion onto the cell surface through a PKA-dependent mechanism (Chao et al., 2002b; Mangiavacchi and Wolf, 2004). However, we were unable to examine the consequences of $\mathrm{D}_{1}$-like receptor stimulation for synaptic targeting of AMPARs because NAc cultures do not contain glutamate neurons and thus do not contain glutamate synapses.

Here we describe the establishment of NAc/PFC cocultures, in which excitatory inputs to NAc neurons are restored by PFC neurons. Using NAc/PFC cocultures, we first investigated the facilitating effect of acute $\mathrm{D}_{1}$-like receptor stimulation and PKA activation on synaptic AMPAR trafficking in NAc neurons. Then, to explore possible consequences of repeated exposure to DAreleasing psychomotor stimulants, we studied the effect of repeated DA treatment on AMPAR synaptic expression, signaling pathways involved in AMPAR trafficking, and the ability of $\mathrm{D}_{1}$ like receptors to modulate AMPAR trafficking.

\section{Materials and Methods}

Animals. All animal use procedures were in strict accordance with the National Institutes of Health Guide for the Care and Use of Laboratory Animals and were approved by the Institutional Animal Care and Use Committee of the Rosalind Franklin University of Medicine and Science. Pregnant Sprague Dawley rats (Harlan, Indianapolis, IN; Zivic Miller, Pittsburgh, PA), obtained at 18-20 d of gestation, were housed individually in breeding cages. One-day-old offspring were decapitated and used to obtain NAc neurons. PFC cells were obtained from enhanced green fluorescent protein (EGFP)-expressing mice [strain: C57BL/6$\operatorname{TgN}(A C T b E G F P) 1 O s b ;$ The Jackson Laboratory, Bar Harbor, ME]. The EGFP transgenic mouse strain was maintained by mating a male hemizygous carrier with a female C57BL/6J mouse. The EGFP-expressing offspring were identified under a fluorescence microscope on postnatal day 1 and decapitated to obtain cells from the prefrontal cortex. In some experiments, PFC cells were obtained from enhanced cyan fluorescent protein (ECFP)-expressing mice [strain: B6.129(ICR)-Tg(ACTBECFP)1Nagy/J; The Jackson Laboratory]. The ECFP transgenic mouse strain was maintained by mating homozygous ECFP male and female mice. All offspring express ECFP.

Postnatal NAc/PFC cocultures. The NAc of postnatal day 1 rats was removed, dissociated with papain (20-25 U/ml; Worthington Biochemical, Lakewood, $\mathrm{NJ}$ ) at $37^{\circ} \mathrm{C}$, and plated at a density of 30000 cells per well onto coverslips coated with poly-D-lysine ( $100 \mu \mathrm{g} / \mathrm{ml}$; Sigma, St. Louis, $\mathrm{MO}$ ) in 24-well culture plates as described previously (Mangiavacchi and Wolf, 2004). The medial PFC of postnatal day 1 EGFP mice was isolated and dissociated with papain $(20-25 \mathrm{U} / \mathrm{ml})$ as described previously for rat PFC (Sun et al., 2005). PFC cells were plated at a density of 20,000 cells per well with the NAc cells described above. NAc/PFC cocultures were grown in Neurobasal medium (Invitrogen, Carlsbad, CA) supplemented with 2 mM GlutaMAX, 0.5\% Gentamicin, and 2\% B27 (Invitrogen). Onehalf of the medium was replaced with this Neurobasal growth medium every $4 \mathrm{~d}$. Cultures were used for experiments between weeks 2 and 3.

In developing this coculture system, we needed to add PFC neurons in sufficient number to restore glutamate input to NAc neurons while at the same time maintaining a cell density sufficiently low to allow image analysis of single neurons. To achieve this, preliminary studies were conducted in which we plated different ratios of PFC neurons (fluorescent cells) to NAc neurons (nonfluorescent cells), as determined by cell counting before plating, and investigated the cells after 2 weeks in vitro. When $100,000,80,000,60,000$, or 40,000 PFC neurons were plated with 30,000 NAc neurons, cortical innervation was high but it was difficult to conduct quantitative image analysis because many cells were confluent and the processes appeared as a dense network. When 10,000 PFC neurons were plated with NAc neurons, analysis of single medium spiny neurons was possible but cortical innervation was low. We found that 20,000 or 30,000 PFC neurons plated with 30,000 NAc neurons yielded the optimal results. The cell density was optimal for image analysis, and many medium spiny neurons were in close proximity to PFC neurons (Fig. $1 A-C$ ).

Immunocytochemistry. Cell surface GluR1 was labeled by incubating live cultures with antibody recognizing the extracellular N-terminal domain of GluR1 (amino acids 271-285; RTSDSRDHTRVDWKR; 1:15; Calbiochem, San Diego, CA) in Neurobasal media for $30 \mathrm{~min}$ at room temperature. Cells were then fixed with $4 \%$ paraformaldehyde in PBS for $15 \mathrm{~min}$, blocked with 5\% donkey serum in PBS for $60 \mathrm{~min}$, and incubated with donkey anti-rabbit secondary antibody conjugated to cyanine 3 (Cy3) (1:500; Jackson ImmunoResearch, West Grove, PA) for $60 \mathrm{~min}$ under nonpermeant conditions. Cells were then permeabilized with $0.1 \%$ Triton X-100 in PBS for 15 min, blocked with 5\% goat serum in PBS for $60 \mathrm{~min}$, and incubated with monoclonal antibody to the synaptic marker synaptobrevin (SB)/vesicle-associated membrane protein 2 (1: 2000 ; overnight at $4^{\circ} \mathrm{C}$; Synaptic Systems, Goettingen, Germany) followed by goat anti-mouse secondary antibody conjugated to Alexa 350 ( $1: 200 ; 1 \mathrm{~h}$ at room temperature; Invitrogen). A punctate pattern of staining was observed for both GluR1 and synaptobrevin on medium spiny neurons in NAc/PFC cocultures. Methods for quantifying total surface GluR1 expression and synaptic GluR1 expression are described below (Data analysis for immunocytochemistry). For cell surface $D_{1}, D_{5}$, or $\mathrm{D}_{2}$ receptor staining, live cells were incubated for $30 \mathrm{~min}$ with polyclonal antibody recognizing the second extracellular domain of the $\mathrm{D}_{1}$ receptor, the third extracellular domain of the $\mathrm{D}_{5}$ receptor, or the $\mathrm{N}$ terminal of the $D_{2}$ receptor $\left(D_{1}\right.$ antibody, 1:100; $D_{5}$ antibody, 1:250; $D_{2}$ antibody, 1:200; gifts from Dr. Marjorie Ariano, Rosalind Franklin University of Medicine and Science). The subtype specificity of the $D_{1}, D_{5}$, and $\mathrm{D}_{2}$ receptor antibodies has been demonstrated (McVittie et al., 1991; Ariano and Sibley, 1994; Ariano et al., 1997a). Then the cells were fixed and incubated with donkey anti-rabbit secondary antibody conjugated to Cy3 (1:500; Jackson ImmunoResearch) at room temperature for $1 \mathrm{~h}$. To determine the location of $\mathrm{D}_{1}$ receptors, the cells were further immunostained for synaptobrevin as described above.

In some studies, we measured glycine-induced synaptic incorporation of GluR1 as described by Lu et al. (2001). Cells were treated with glycine $(1 \mu \mathrm{M})$ for $3 \mathrm{~min}$ at room temperature in bathing solution $(140 \mathrm{~mm} \mathrm{NaCl}$, $1.3 \mathrm{~mm} \mathrm{CaCl}_{2}, 5.0 \mathrm{~mm} \mathrm{KCl}, 25 \mathrm{~mm}$ HEPES, $10 \mathrm{~mm}$ glucose, and $0.5 \mu \mathrm{M}$ TTX, pH 7.4) and then transferred to bathing solution without glycine for $15 \mathrm{~min}$. Cells were then immunostained for newly externalized GluR1 and synaptobrevin as described below.

In experiments shown in Figures 3, 4, and 5A (and supplemental Figs. $2 A, 3$, available at www.jneurosci.org as supplemental material), we selectively detected insertion of new GluR1-containing receptors onto the cell surface using a preblocking method modified from Lu et al. (2001). To block existing cell surface GluR1, live cells were first incubated with N-GluR1 antibody (1:15 in Neurobasal growth media) for $30 \mathrm{~min}$ and then incubated with nonconjugated goat anti-rabbit secondary antibody $\left(5 \mu \mathrm{g} / \mathrm{ml}\right.$; Sigma) for $30 \mathrm{~min}$ at $15^{\circ} \mathrm{C}$ in a $3 \% \mathrm{CO}_{2}$ refrigerated incubator (Tritech Research, Los Angeles, CA). Then, cells were brought to room temperature, in either control media or media containing test drugs, to allow insertion of new AMPARs into the cell membrane. After this incubation, cultures were rinsed and fixed with $4 \%$ paraformaldehyde in PBS for $10 \mathrm{~min}$ at room temperature. To detect newly inserted GluR1, cultures were subsequently incubated with N-GluR1 antibody (1:15) at room temperature for $1 \mathrm{~h}$, blocked with $5 \%$ donkey serum, and incubated with Cy3-conjugated donkey anti-rabbit secondary antibody (1: 500 ) at room temperature for $1 \mathrm{~h}$. To determine the location of newly inserted GluR1, synapses were immunostained with mouse monoclonal antibody to synaptobrevin (1:2000) and Alexa 350 donkey anti-mouse IgG (1:200) after permeabilization with $0.1 \%$ Triton X-100 in PBS for 15 
min and incubation with 5\% goat serum in PBS for 1 h. For coculture experiments in which the PFC was obtained from ECFP-expressing mice, Alexa 488 donkey anti-mouse IgG (1:1000; Invitrogen) was used as the secondary antibody.

Data analysis for immunocytochemistry. Images were acquired and analyzed with an imaging system consisting of a Nikon (Melville, NY) inverted microscope, ORCA-ER digital camera, and MetaMorph software (Universal Imaging, Downingtown, PA). Images for all experimental groups were taken using identical acquisition parameters. All groups to be compared were processed simultaneously using cells from the same culture preparation. For each experimental group, cells from at least four different wells were used, and approximately six cells from each well were analyzed. Neuronal subtypes in the NAc were distinguished based on previously defined morphological criteria (Shi and Rayport, 1994; Chao et al., 2002b). Medium spiny neurons, the predominant cell type in the NAc, were identified by a soma diameter of $\sim 10-15 \mu \mathrm{m}$, with two to four relatively closely projecting processes. Interneurons were identified by a soma diameter $>15 \mu \mathrm{m}$ with extended processes over 10 times the length of the soma. The soma was excluded from analysis because, in the intact brain, glutamate synapses from PFC onto medium spiny neurons occur exclusively on processes (Meredith and Totterdell, 1999), and nearly all GluR1 immunostaining is observed on processes, not on the soma (Chen et al., 1998). Neuronal processes were selected for analysis under phasecontrast imaging to avoid the possibility of experimenter bias based on the intensity of fluorescence staining. For each image, the total area of fluorescently labeled surface GluR1 in a fixed length of process $(15 \mu \mathrm{m})$ was measured using a threshold set at least two times higher than average background fluorescence in processes of untreated cells. The same approach was used to define the area of synaptobrevin staining (SB area). Nonsynaptic GluR1 area was defined as the area of GluR1 staining (in arbitrary units) that did not overlap with synaptobrevin staining. Synaptic GluR1 area was defined as the area of GluR1 staining (in arbitrary units) that overlapped with synaptobrevin staining. Another parameter, the percentage of synaptic area containing new GluR1 (or synaptic GluR1 incorporation), was quantified as the percentage of total synaptobrevin staining that overlapped with new GluR1 staining [(SB + GluR1 area)/ total SB area $\times 100]$. Because of limitations of light microscopy, a concern is that colocalization with a synaptic marker may not be sufficient to distinguish between synaptic and perisynaptic GluR1. However, analysis of striatal medium spiny neurons using the postembedding immunogold method revealed low levels of perisynaptic GluR1, whereas $\sim 85 \%$ of the GluR1 immunoparticles on the postsynaptic surface of the spine were located within the postsynaptic density (Bernard et al., 1997). In Figure $2 F$, we were unable to normalize to synaptobrevin area because it was altered by the experimental manipulation, so synaptic GluR1 incorporation was expressed as the percentage of cell surface GluR1 area found in synapses $[(\mathrm{SB}+\mathrm{GluR} 1$ area $) /$ surface GluR1 area $\times 100]$. All values refer to mean \pm SEM. Independent group $t$ tests were used for comparing two groups. For multiple groups, we used ANOVA followed by an appropriate post hoc test ( $n=$ number of cells analyzed).

Surface receptor crosslinking with bis(sulfosuccinimidal)suberate. After two washes with HBSS (Invitrogen), cultures were incubated with $2 \mathrm{~mm}$ bis(sulfosuccinimidal)suberate (BS ${ }^{3}$ ) (Pierce, Rockford, IL) in HBSS for 10 min with agitation at $37^{\circ} \mathrm{C}$ (Hall and Soderling, 1997a,b; Hall et al., 1997). Crosslinking was terminated by quenching the reaction with 100 $\mathrm{mm}$ glycine for $10 \mathrm{~min}$ at $4^{\circ} \mathrm{C}$.

Western blotting. Cultures were scraped into ice-cold buffer containing protease and phosphatase inhibitors [25 mM HEPES, pH 7.4, $500 \mathrm{~mm}$ $\mathrm{NaCl}, 2$ mм EDTA, 1 mм DTT, 1 mм phenylmethyl sulfonyl fluoride, 20 mм NaF, 1 mm sodium orthovanadate, $10 \mathrm{~mm}$ sodium pyrophosphate, 1 $\mu \mathrm{M}$ microcystin-LF, $1 \mu \mathrm{M}$ okadaic acid, $1 \times$ protease inhibitor cocktail set I (Calbiochem), and $0.1 \%$ Nonidet P-40 (v/v)]. Homogenates were obtained by sonicating culture suspensions three times for $5 \mathrm{~s}$ each time on ice and centrifuging at $12,000 \times g$ for $5 \mathrm{~min}$. The supernatant was then aliquotted and stored at $-80^{\circ} \mathrm{C}$. Protein concentration was determined by the Bio-Rad assay (Bio-Rad, Hercules, CA). Samples $(20 \mu \mathrm{g}$ total protein per lane) were run on a 3-8\% gradient Tris-acetate gel (Invitrogen) or $10 \%$ bis-Tris gel (Invitrogen) under reducing conditions, and proteins were transferred onto polyvinylidene difluoride (PVDF) mem- branes for immunoblotting. Membranes were washed in double-distilled $\mathrm{H}_{2} \mathrm{O}\left(\mathrm{ddH}_{2} \mathrm{O}\right)$ and blocked with $1 \%$ goat serum or $5 \%$ nonfat dry milk in TBS-Tween 20 (TBS-T), pH 7.4, or with 3\% BSA (Sigma) in TBS-T for $1 \mathrm{~h}$ at room temperature. Membranes were then incubated with one of the following phospho-antibodies overnight at $4^{\circ} \mathrm{C}$ : P-Ser845 GluR1 (1: 500; Phosphosolutions, Aurora, CO), P-Ser831 GluR1 (1:500; Millipore Bioscience Research Reagents, Temecula, CA), P-Thr286 Ca ${ }^{2+} /$ calmodulin dependent protein kinase II (CaMKII) (1:10,000; Phosphosolutions), phosphorylated extracellular signal-regulated kinase 44/42 (PERK44/42) (1:10 000; Millipore Bioscience Research Reagents), or an antibody recognizing phosphorylated PKA substrates (1:2500; Cell Signaling, Danvers, MA). The PKA substrate antibody was produced by immunizing rabbits with a synthetic phospho-PKA substrate peptide and purified over an affinity column using the same peptide. Overlapping substrate specificity with other Arg-directed protein kinases with similar Arg requirements [e.g., AKT and to a lesser extent protein kinase $\mathrm{C}(\mathrm{PKC})$ ] relative to the phosphorylated Ser/Thr (Kennelly and Krebs, 1991; Pearson and Kemp, 1991) is a potential concern for experiments with the PKA substrate antibody. To assess this, we compared the PKA substrate antibody with the AKT substrate antibody (Cell Signaling Technology) in Western blotting experiments using rat NAc tissue and found that the antibodies produced completely different banding patterns. Of the nine major bands detected under our conditions with the PKA substrate antibody, none were detected with the AKT substrate antibody. Furthermore, only the PKA substrate antibody showed increased immunoreactivity by Western blotting in tissue that was stimulated with the PKA activator Sp-adenosine 3',5' -cyclic monophosphorothioate triethylammonium salt (SpcAMPS) or the $\mathrm{D}_{1}$-like agonist SKF 81297 [( \pm )-6-chloro-7,8-dihydroxy-1-phenyl-2,3,4,5-tetrahydro- $1 H$ 3-benzazepine hydrobromide] (SKF). Similarly, the PKC substrate antibody (Cell Signaling Technology) produced a significantly different banding pattern, and the peptide used to raise the PKC substrate antibody did not diminish immunoreactivity detected with the PKA substrate antibody (data not shown). After incubation with primary antibodies, membranes were washed extensively with TBS-T solution, incubated for 60 min with HRP-conjugated anti-rabbit IgG (1:10,000; Upstate Cell Signaling, Lake Placid, NY), and washed extensively again in TBS-T. Membranes were then rinsed with $\mathrm{ddH}_{2} \mathrm{O}$ and immersed in enhanced chemiluminescence (ECL) detecting reagent that included luminol as a substrate and phenols as enhancers (GE Healthcare, Little Chalfont, UK) for $1 \mathrm{~min}$. Images were collected on a Versa Doc Model 5000 (Bio-Rad) for $1 \mathrm{~s}$ to $5 \mathrm{~min}$. Phospho-antibodies were stripped from the membrane by incubating in $62.5 \mathrm{~mm}$ Tris, $\mathrm{pH} 6.8,2 \%$ SDS, and $100 \mathrm{~mm}$ 2-mercaptoethanol at $65^{\circ} \mathrm{C}$ for $60 \mathrm{~min}$ or in Re-blot Plus Solution (Millipore Bioscience Research Reagents) at room temperature for $30 \mathrm{~min}$. Blots were then probed with a phosphorylation-independent antibody to GluR1 (1:500; Millipore Bioscience Research Reagents), $\alpha$ CaMKII (1: 20,000; Millipore Bioscience Research Reagents), $\beta$ CaMKII (1:500; Abcam, Cambridge, MA), or ERK44/42 (1:10,000; Millipore Bioscience Research Reagents). We conducted positive control experiments to confirm specificity of the phospho-specific antibodies based on the ability of $D_{1}$ like receptor stimulation to activate PKA and ERK (Neve et al., 2004) and the ability of phorbol esters to activate PKC. Immunoreactivity detected with P-845 GluR1 and P-ERK44/42 antibodies (as well as the PKA substrate antibody; see above) was significantly greater in tissue incubated with SKF 81297 (10 $\mu \mathrm{M}, 15 \mathrm{~min})$, and P-831 GluR1 immunoreactivity was significantly greater in tissue incubated with phorbol-12-myristate13 -acetate ( $1 \mu \mathrm{M}, 3 \mathrm{~h}$; Calbiochem) (data not shown). For protein crosslinking experiments, samples were loaded onto $4-15 \%$ Bio-Rad Tris- $\mathrm{HCl}$ gels and transferred to PVDF membranes as described above. Blots were probed with antibodies to NR2A (1:500; Santa Cruz Biotechnology, Santa Cruz, CA) and NR2B (1:500, Calbiochem). For supplemental Figure $2 B$ (available at www.jneurosci.org as supplemental material), blots were probed with antibody to Arc (1:1000; Santa Cruz Biotechnology). To measure total $\mathrm{D}_{1}$ receptor protein after repeated DA treatment, we quantified a doublet at $\sim 74 \mathrm{kDa}$ (1:200; Santa Cruz Biotechnology); previous studies have shown that, when cells are prepared in lysis buffer containing DTT to dissociate dimers (Lee et al., 2003b), this $\mathrm{D}_{1}$ receptor antibody reacts predominantly with two bands of $\sim 74 \mathrm{kDa}$, 

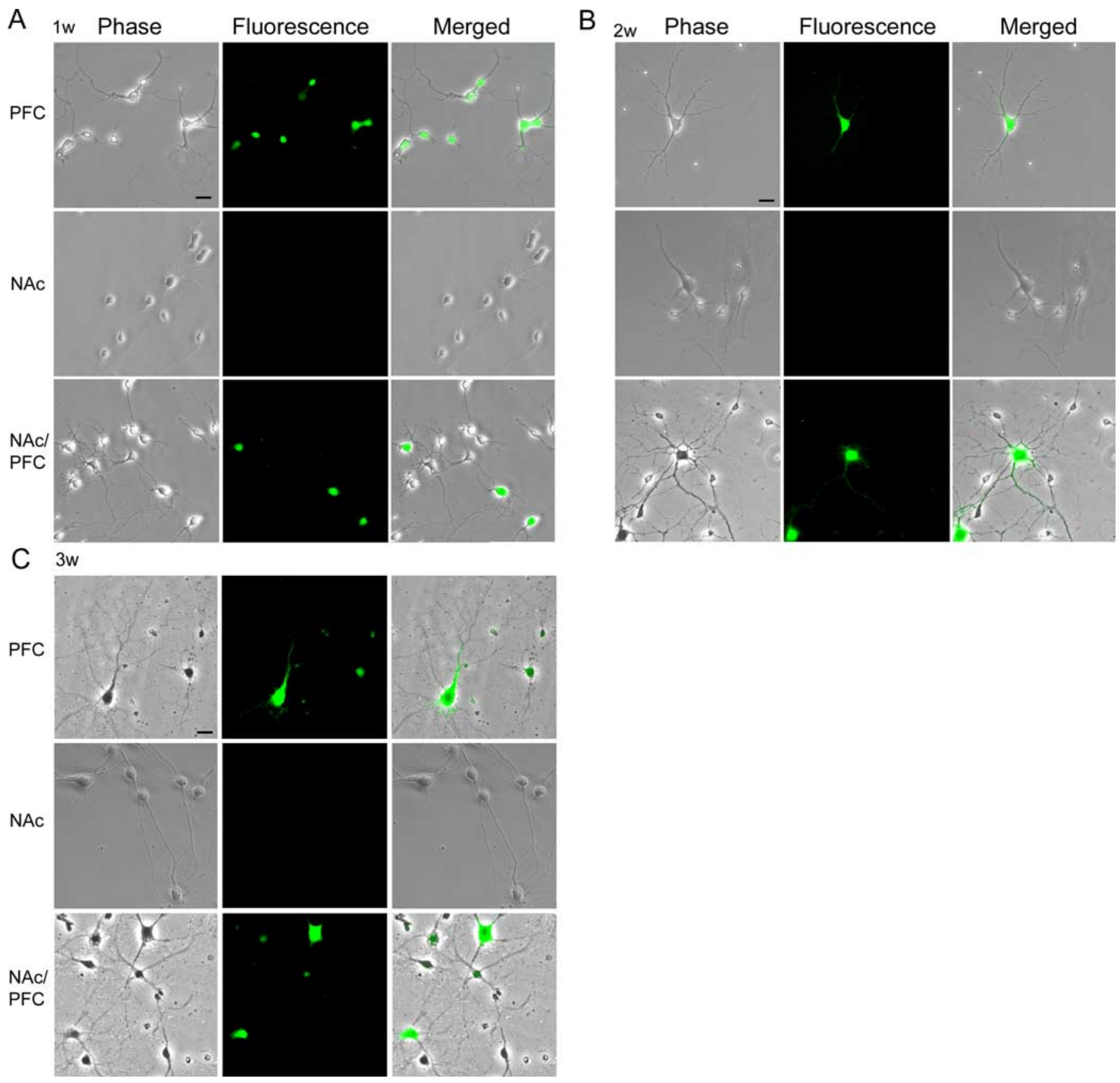

Figure 1. Comparison of PFC cultures, NAc cultures, and NAc/PFC cocultures after 1 week $(\boldsymbol{A}), 2$ weeks $(\boldsymbol{B})$, or 3 weeks $(\boldsymbol{C})$ in culture. PFC cells were obtained from EGFP mice and NAccells from rats. In cocultures, cells with the morphology of medium spiny neurons (the predominant cell type in NAc) were not fluorescent, whereas cells with the morphology of pyramidal neurons (from PFC) expressed EGFP. Many medium spiny neurons cluster near pyramidal neurons and their processes were sometimes apposed. Scale bar, $20 \mu \mathrm{m}$.

which corresponds to the size of glycosylated $\mathrm{D}_{1}$ receptors (Bergson et al., 1995; Karpa et al., 1999). For all experiments, total protein in each lane was determined by staining membranes with Ponceau S (Sigma). The optical density of each band was determined using TotalLab (Nonlinear Dynamics, Newcastle, UK). For the PKA substrate antibody, the entire lane was scanned so that our assessment would be based on multiple substrates. The control and repeated DA treatment groups were compared by a $t$ test. Significance was set at $p<0.05$.

\section{Results}

\section{Characterization of NAc/PFC cocultures}

To enable the study of excitatory synapses onto NAc neurons while preserving the ability to identify NAc neurons, we established a coculture system consisting of rat NAc neurons and PFC neurons from EGFP transgenic mice. In pure PFC cultures pre- pared from EGFP transgenic mice, all neurons express EGFP, which can be readily detected by fluorescence microscopy after 1 , 2 , or 3 weeks in cultures (Fig. $1 A-C$, respectively). In pure NAc cultures prepared from rats, no neurons express EGFP (Fig. $1 A-$ $C)$. In NAc/PFC cocultures, cells with the morphology of pyramidal neurons from PFC express EGFP, whereas cells with the morphology of medium spiny neurons from NAc do not (Fig. $1 A-C)$. Many medium spiny neurons are located near pyramidal cells, and their processes are sometimes apposed (Fig. 1A-C). Thus, this coculture system enables us to easily distinguish NAc cells from PFC cells under fluorescence microscopy. Our approach can be widely applied to other studies that require distinguishing between two cell sources.

To determine how addition of PFC cells might influence the 
properties of NAc neurons, we conducted several experiments comparing pure NAc cultures and NAc/PFC cocultures. First, we determined the relative number of medium spiny neurons and interneurons, based on analysis of $\sim 300$ cells for each culture system (cells were from randomly selected fields in four wells). In NAc/PFC cocultures, $\sim 78 \%$ of the NAc cells were medium spiny neurons and $\sim 22 \%$ were interneurons. This is similar to results in pure NAc cultures ( $\sim 80 \%$ medium spiny neurons and $\sim 20 \%$ interneurons) and with our previous report (Chao et al., 2002b). Next, we determined whether restoring excitatory inputs by adding PFC neurons influenced DA receptor surface expression on medium spiny NAc neurons. Cell surface $\mathrm{D}_{1}$ and $\mathrm{D}_{5}$ DA receptors were labeled by incubating live cultures ( 3 weeks old) with antibodies to extracellular epitopes of these receptors. Medium spiny neurons in NAc/PFC cocultures exhibited punctate cell surface expression of $\mathrm{D}_{1}$ and $\mathrm{D}_{5} \mathrm{DA}$ receptors (Fig. $2 \mathrm{~A}$ ). Similar staining was observed for pure NAc cultures (data not shown). To determine the percentage of medium spiny neurons that exhibited $D_{1}$ or $D_{5}$ receptor surface expression, we analyzed $\sim 500$ neurons from each culture system (cells were from randomly selected fields in six wells). In NAc/PFC cocultures, $\sim 70 \%$ of medium spiny neurons were $\mathrm{D}_{1}$ receptor positive, $\sim 85 \%$ were $\mathrm{D}_{5}$ receptor positive, and $\sim 87 \%$ were labeled when $\mathrm{D}_{1}$ and $\mathrm{D}_{5}$ antibodies were used together. Very similar results were obtained for pure NAc cultures, in which $\sim 75 \%$ of medium spiny neurons were $\mathrm{D}_{1}$ receptor positive, $\sim 85 \%$ were $D_{5}$ receptor positive, and $\sim 89 \%$ were labeled when $\mathrm{D}_{1}$ and $\mathrm{D}_{5}$ antibodies were used together. The expression of cell surface $\mathrm{D}_{2}$ receptors in the two culture systems was also compared, and no differences were found $(\sim 80 \%$ of medium spiny neurons were $\mathrm{D}_{2}$ receptor positive in both pure NAc cultures and NAc/PFC cocultures). These results indicate a high degree of $\mathrm{D}_{1}$ and $\mathrm{D}_{2}$ receptor colocalization in cultured NAc medium spiny neurons. However, the degree of colocalization of $\mathrm{D}_{1}$ and $\mathrm{D}_{2}$ receptors in vivo remains controversial. Some studies reported nearly complete segregation or that only a small portion $(<20 \%)$ of projection neurons in dorsal striatum or NAc expressed both $\mathrm{D}_{1}$ and $\mathrm{D}_{2}$ receptors (Gerfen et al., 1990; Le Moine et al., 1991; Le Moine and Bloch, 1995; Deng et al., 2006). However, other studies found that $\mathrm{D}_{1}$ and $\mathrm{D}_{2}$ receptors were coexpressed by a greater percentage of dorsal striatal projection neurons, albeit at different levels in different striatal populations, with estimates ranging from 30 to $40 \%$ (Meador-Woodruff et al., 1991; Ariano et al., 1992; Ariano and Sibley, 1994) to nearly all striatal neurons (Aizman et al., 2000).

Double immunostaining of the presynaptic marker synaptobrevin and cell surface $\mathrm{D}_{1}$ receptors in NAc/PFC cocultures demonstrated that most surface $D_{1}$ receptors were located at extrasynaptic sites on medium spiny NAc neurons (Fig. 2B), consistent with previous studies of striatal neurons (see Discussion). From this point forward, we will use the term $D_{1}$-like to refer to the $D_{1}$ family of receptors (which includes the $D_{5}$ receptor) because agonists and antagonists used in our studies act on both $\mathrm{D}_{1}$ and $\mathrm{D}_{5}$ receptors.

Finally, we determined whether addition of PFC cells altered GluR1 surface expression or synapse formation onto medium spiny neurons. Surface GluR1 and the synaptic marker synaptobrevin were stained in pure NAc cultures and NAc/PFC cocultures after 3 weeks in culture. Most medium spiny neurons in both culture systems were GluR1 positive, consistent with in vivo findings in the adult rat striatum (Bernard et al., 1997; Chen et al., 1998). GluR1 surface expression on process segments, classified according to their distance from the soma $(0-15,15-30$, or $30-45 \mu \mathrm{m})$, did not differ significantly between medium spiny neurons in the two culture systems, although there was a trend toward an increase in the NAc/PFC cocultures (Fig. 2D). Medium spiny neurons in NAc/PFC cocultures showed significant increases in both synaptobrevin expression and the percentage of cell surface GluR1 found in synapses (Fig. 2C,E,F). In addition, we found that the presence of PFC neurons significantly increased spine formation by the medium spiny NAc neurons (supplemental Fig. 1, available at www.jneurosci.org as supplemental material). In NAc/PFC cocultures, $40 \pm 7 \%$ of GluR1-positive puncta was located within spines. Our results are similar to those of Segal et al. (2003) who demonstrated that addition of mouse cortical neurons to cultured rat striatal neurons resulted in increased spine density and the appearance of spontaneous and evoked excitatory synaptic currents in the striatal neurons. The existence of synaptic GluR1 on medium spiny neurons in NAc/ PFC cocultures establishes the coculture system as useful for studying AMPAR synaptic trafficking.

\section{The $\mathrm{D}_{1}$-like receptor agonist SKF 81297 increases cell surface GluR1 but not GluR1 synaptic incorporation in medium spiny neurons}

We showed previously that the $\mathrm{D}_{1}$-like receptor agonist SKF 81297 increased GluR1 insertion onto the surface of medium spiny neurons in pure NAc cultures (Mangiavacchi and Wolf, 2004). In the present study, we extended these results by determining the effect of SKF 81297 on GluR1 synaptic targeting using NAc/PFC cocultures. A preblocking method modified from Lu et al. (2001) was used to selectively detect newly inserted GluR1 on medium spiny neurons. Briefly, preexisting cell surface GluR1 was preblocked by incubating cultures with primary antibody and nonconjugated secondary antibody at $15^{\circ} \mathrm{C}$. Then, cells were brought to room temperature for $15 \mathrm{~min}$ to allow insertion of new GluR1-containing receptors (timing based on Mangiavacchi and Wolf, 2004). Newly inserted GluR1 was detected with a second round of immunostaining under nonpermeant conditions with Cy3-conjugated secondary antibody. Finally, cells were stained for synaptobrevin under permeant conditions to determine whether the insertion of GluR1 occurred at synapses.

In NAc/PFC cocultures, medium spiny neurons treated with SKF $81297(1 \mu \mathrm{M})$ for $15 \mathrm{~min}$ exhibited higher levels of new surface GluR1 area than control cultures (Fig. $3 A, B$ ). This effect was blocked when the $\mathrm{D}_{1}$-like receptor antagonist SCH 23390 [R-(+)-7-chloro-8-hydroxy-3-methyl-1-phenyl-2,3,4,5-tetrahydro- $1 H$-3-benzazepine hydrochloride] $(10 \mu \mathrm{M})$ was added $5 \mathrm{~min}$ before SKF 81297. When given alone, SCH 23390 had no effect on GluR1 insertion (Fig. 3B). SKF did not increase the percentage of synaptic area containing new GluR1 (Fig. 3C) or new synaptic GluR1 area (Fig. 3D), whereas nonsynaptic GluR1 area was significantly increased by SKF 81297 treatment (Fig. 3E). These results indicate that SKF 81297 increased GluR1 insertion onto the cell surface but not its synaptic incorporation in medium spiny neurons. Based on the fact that $\mathrm{D}_{1}$-like receptor agonists also increased GluR1 insertion in pure NAc cultures (above), we conclude that $\mathrm{D}_{1}$-like receptor agonists are increasing GluR1 insertion in NAc/PFC cocultures by interacting directly with $D_{1}$-like receptors on NAc neurons rather than indirectly via $\mathrm{D}_{1}$-like receptors on $\mathrm{PFC}$ neurons.

A caveat should be noted regarding methods used to analyze synaptic GluR1 in Figure 3 and subsequent experiments. Although results in Figures 4 and 5 provide positive controls for our ability to detect an increase in synaptic GluR1, it is possible that the sensitivity of our methods is adequate to detect GluR1 addition to silent synapses but not GluR1 addition to synapses already 
A

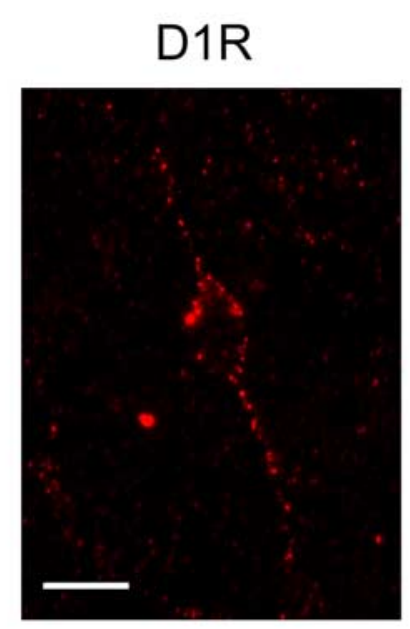

D1R

GluR1
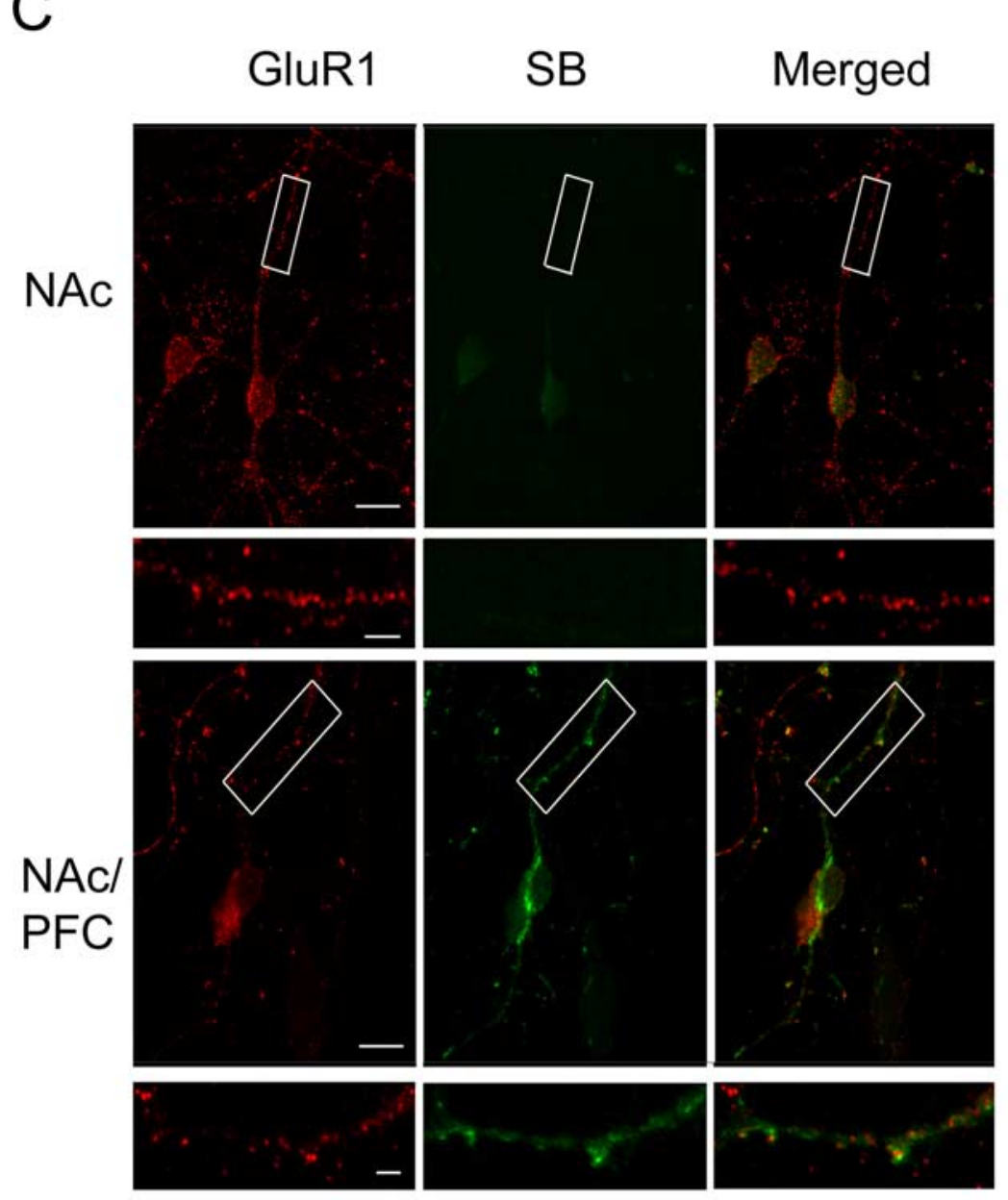

D5R

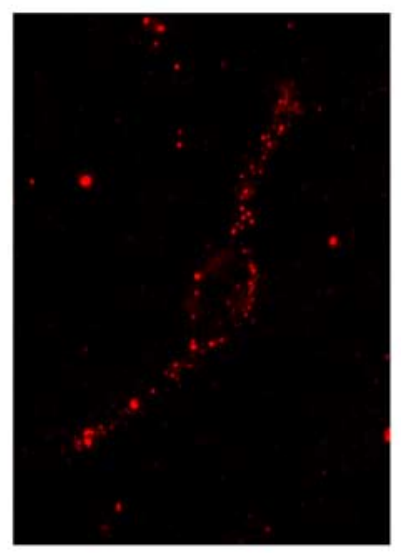

B

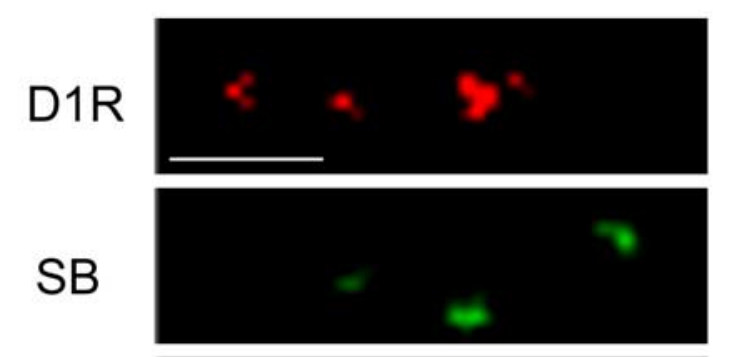

Merged

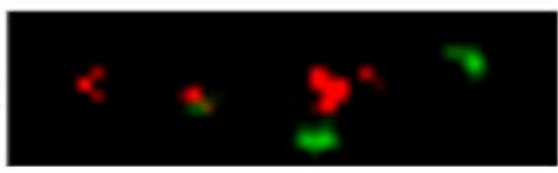

D
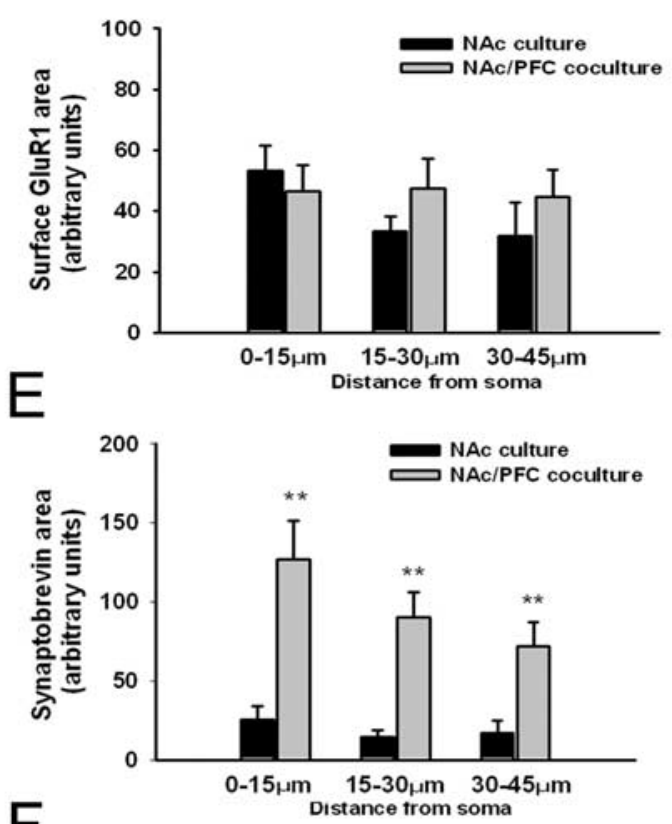

$\mathrm{F}$

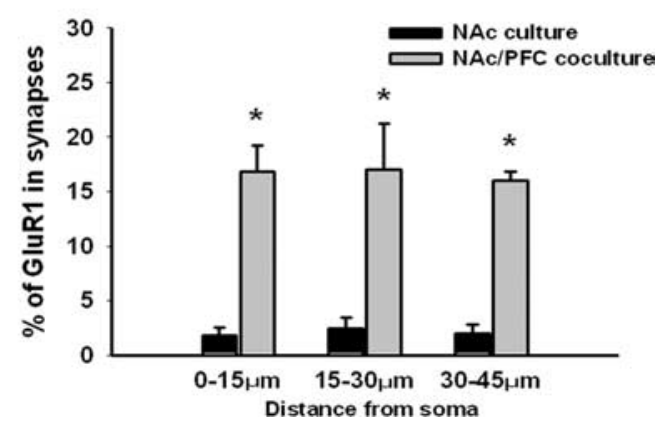

Figure 2. Cell surface expression of $D_{1}$ DA receptors, $D_{5}$ DA receptors, and GluR1-containing AMPARs on medium spiny NAc neurons in NAc/PFC cocultures. After 3 weeks in vitro, cultures were immunostained for cell surface $D_{1}$ or $D_{5}$ receptors, cell surface GluR1, and the synaptic marker SB as described in Materials and Methods. $A$, Medium spiny neurons in NAc/PFC cocultures exhibited punctate cell surface expression of $D_{1}$ receptors and $D_{5}$ receptors. Scale bar, $20 \mu \mathrm{m}$. $B$, Double staining of $S B$ and $D_{1}$ receptors showed that most $D_{1}$ receptors are located at extrasynaptic sites on the processes of medium spiny neurons. $D_{1}$ receptors were detected with Cy3 secondary antibody (red), whereas synaptobrevin was detected with Alexa 350 (original color was blue; green pseudocolor is used for clarity). Scale bar, $2 \mu \mathrm{m}$. C, Representative images of surface GluR1 and SB double staining in pure NAc cultures and NAc/PFC cocultures. GluR1 was detected with Cy3 secondary antibody (red), whereas SB was detected with Alexa 350 (green pseudocolor). Scale bars, $20 \mu \mathrm{m}$ for large panels. Higher-power views of selected areas (white squares) are also shown (scale bars, $5 \mu \mathrm{m}$ ). $\boldsymbol{D}$, Comparison of GluR1 surface expression on process segments $(0-15,15-30$, or $30-45 \mu \mathrm{m}$ from the soma) of medium spiny neurons in pure NAc cultures $(n=19)$ and NAc/PFC cocultures $(n=$ 22). Coculture of NAc neurons with PFC neurons did not significantly change GluR1 surface expression. $E$, Coculture of NAc neurons with PFC neurons increased SB expression on medium spiny neuron processes $\left({ }^{* *} p<0.01, t\right.$ test, compared with pure NAc cultures). $\boldsymbol{F}$, Coculture increased the percentage of cell surface GluR1 found in synapses [(GluR1 + SB area) $/$ surface GluR1 area $\left.\times 100\right]\left({ }^{*} p<\right.$ $0.05, t$ test, compared with pure NAc cultures). 
A
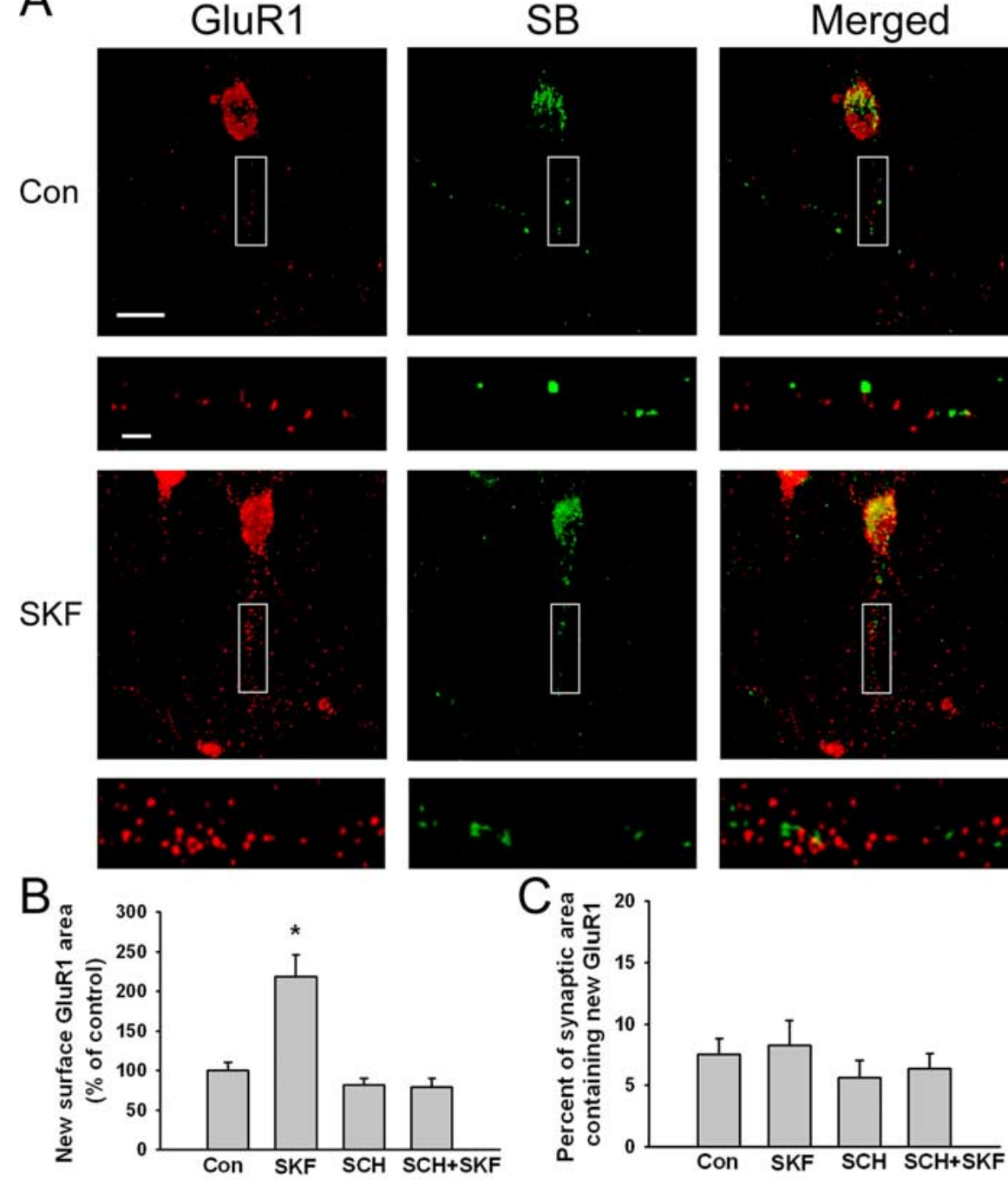

D

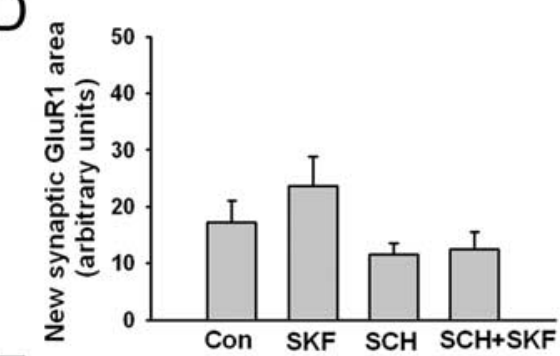

$\mathrm{F}$

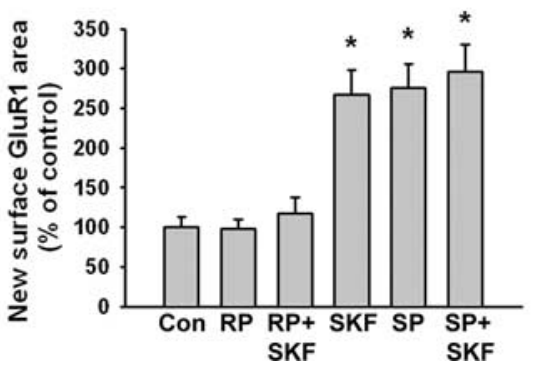

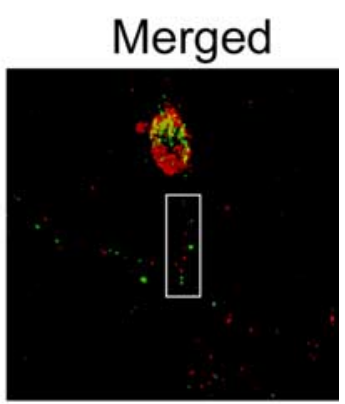
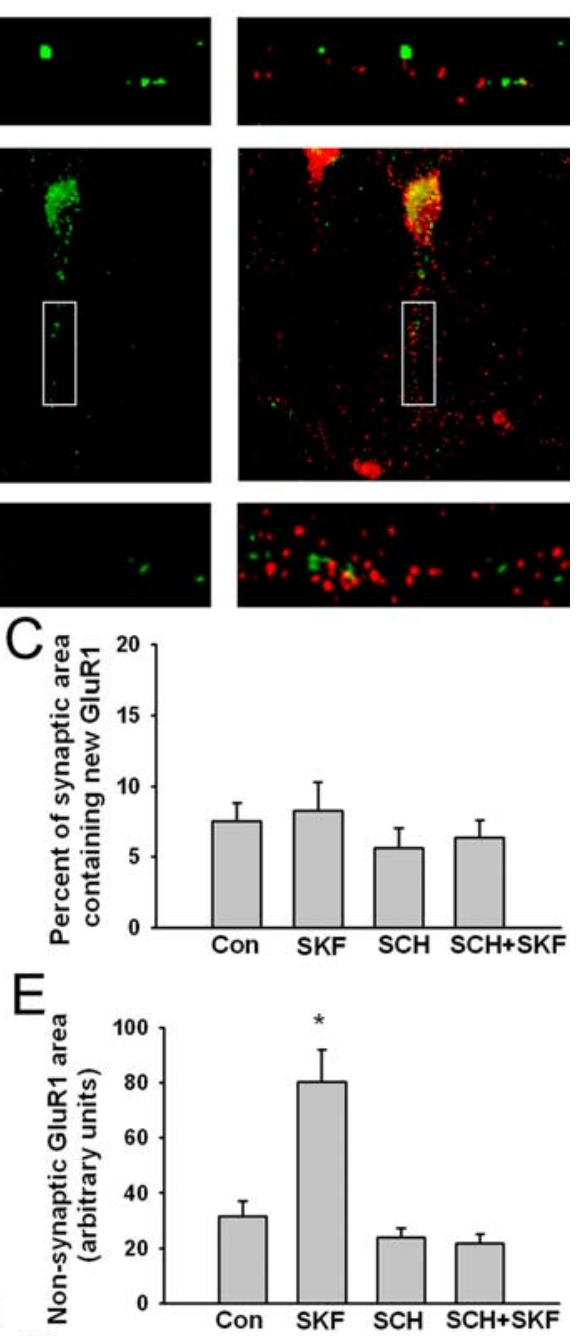

G

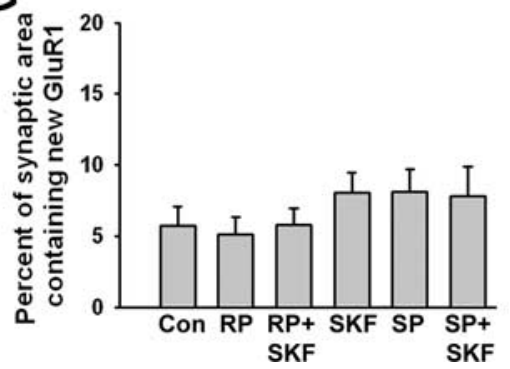

Figure 3. The $D_{1}$-like receptor agonist SKF 81297 increased GluR1 insertion onto the extrasynaptic cell surface in medium spiny NAc neurons through a PKA-dependent pathway. A preblocking method was used to selectively detect newly inserted GluR1. $\boldsymbol{A}$, Examples of newly inserted GluR1 on processes of control (Con) and SKF-treated neurons (1 $\mu \mathrm{m}, 15 \mathrm{~min}$ ), shown with SB staining after permeabilization. GluR1 was detected with Cy3 secondary antibody (red), whereas SB was detected with Alexa 350 (original color was blue; green pseudocolor is used for clarity). Scale bars, $10 \mu \mathrm{m}$ for large panels. Higher-power views of selected areas (white squares) are also shown (scale bar, $5 \mu \mathrm{m}$ ). B, Effect of SKF on GluR1 surface insertion ( $n=17-24$, Dunn's test, ${ }^{*} p<0.05$

expressing GluR1. It is therefore possible that we failed to detect a $\mathrm{D}_{1}$-like agonist effect on GluR1-containing synapses in Figure 3, although it seems unlikely that $\mathrm{D}_{1}$-like receptors would selectively influence GluR1-containing synapses but not silent synapses.

Increased GluR1 cell surface insertion induced by $D_{1}$-like receptor stimulation requires PKA activation

$\mathrm{D}_{1}$ family receptors are positively coupled to adenylyl cyclase (Neve et al., 2004). In pure NAc cultures, we showed that PKA activity was required for $\mathrm{D}_{1}$-like agonistinduced increases in GluR1 surface expression (Chao et al., 2002b; Mangiavacchi and Wolf, 2004). Using cocultures, we extended these studies by examining the role of PKA in AMPAR synaptic targeting. After preblocking, NAc/PFC cocultures were incubated for 15 min with SpcAMPS $(10 \mu \mathrm{M})$, a potent membrane-permeable PKA activator. SpcAMPS significantly increased new surface GluR1 area on medium spiny neurons but did not significantly alter GluR1 synaptic incorporation (Fig. $3 F, G$ ). Thus, as was found for $\mathrm{D}_{1}$-like receptor stimulation, PKA activation is sufficient for increasing surface expression, but not synaptic delivery, of GluR1containing AMPARs. To determine whether PKA activation mediates the ef-

$\leftarrow$

compared with control group, SCH group, and SCH + SKF group). Results are presented as the mean area of GluR1 puncta, normalized to controls. Total incubation time was 20 min. Vehicle or the $D_{1}$-like antagonist SCH $23390(\mathrm{SCH} ; 10 \mu \mathrm{m})$ were present throughout, and SKF (1 $\mu \mathrm{m})$ was added for the final $15 \mathrm{~min}$. C, The percentage of synaptic area containing new GluR1 was determined as the percentage of total SB staining that overlaps with new GluR1 staining [(SB + GluR1 area)/ total SB area $\times 100]$. This parameter was not altered by SKF treatment ( $n=17-24 ;$ ANOVA, $p>0.05)$. D, Quantification of synaptic GluR1 area (area of surface GluR1 staining that overlapped with SB staining) ( $n=17-24$; ANOVA, $p>0.05)$. $\boldsymbol{E}$, Quantification of nonsynaptic GluR1 area (area of surface GluR1 staining that did not overlap with SB) ( $n=17-24$; Dunn's test, ${ }^{*} p<0.05$ compared with control group, SCH group, and SCH + SKF group). $\boldsymbol{F}$, The PKA activator SpcAMPS occluded the effect of the $D_{1}$-like agonist SKF 81297 on GluR1 cell surface insertion, and the PKA inhibitor RpcAMPS blocked the increase in GluR1 insertion produced by SKF 81297 . Total incubation time was $20 \mathrm{~min}$. SpcAMPS and RpcAMPS were present throughout $(10 \mu \mathrm{M})$, and SKF $(1 \mu \mathrm{M})$ was added for the final $15 \mathrm{~min}$. Results are presented as the mean area of GluR1 puncta, normalized to controls. The SKF, SpcAMPS, and SpcAMPS + SKF groups differed significantly from the control group ( $n=19-31$; Dunn's test, ${ }^{*} p<0.05$ compared with control group, RpcAMPS group, and RpcAMPS + SKF group). G, The percentage of synaptic area containing new GluR1 [(SB + GluR1 area)/total SB area $\times 100$ ] was not altered by SKF, SpcAMPS, RpcAMPS, or combined treatment with SKF and SpcAMPS or RpcAMPS $(n=$ 19-31; ANOVA, $p>0.05)$. 
fect of $D_{1}$-like receptor stimulation, we examined the effect of PKA inhibitors and activators in combination with SKF 81297. After preblocking, cultures were incubated for 20 min with Rpadenosine 3',5'-cyclic monophosphorothioate triethylammonium salt (RpcAMPS) (10 $\mu \mathrm{M})$, a membrane-permeable PKA inhibitor, or a maximally effective concentration of SpcAMPS $(10 \mu \mathrm{M})$. Then the $\mathrm{D}_{1}$-like agonist SKF $81297(1 \mu \mathrm{M})$ was added for the final $15 \mathrm{~min}$ of the incubation. RpcAMPS had no effect on its own but blocked the $\mathrm{D}_{1}$-like agonist-induced increase in new GluR1 cell surface insertion (Fig. $3 F$ ). After PKA activation by SpcAMPS, SKF 81297 failed to further increase GluR1 insertion (Fig. $3 F$ ). Thus, PKA inhibition prevented the effect of $D_{1}$-like receptor stimulation, whereas PKA activation occluded it. The effect of these experimental manipulations on GluR1 synaptic incorporation was also determined. GluR1 synaptic incorporation was not altered by SKF 81297, SpcAMPS, RpcAMPS, or the combined administration of RpcAMPS or SpcAMPS with SKF 81297 (Fig. 3G). This was confirmed by analysis of synaptic GluR1 area and nonsynaptic GluR1 area (data not shown).

\section{Regulation of AMPAR trafficking in medium spiny NAc neurons by $D_{1}$ family receptors is independent of protein synthesis}

Smith et al. (2005) reported that incubation of hippocampal cultures with a $\mathrm{D}_{1}$-like agonist $[100 \mu \mathrm{M}$ SKF $38393[( \pm)-1$ phenyl-2,3,4,5-tetrahydro-(1H)-3-benzazepine-7,8-diol hydrochloride] or $10 \mu \mathrm{M}$ dihydrexidine; $15 \mathrm{~min}$ ] increased GluR1 surface expression through a mechanism that required PKA activity and protein synthesis. To test the role of protein synthesis in $\mathrm{D}_{1}$-like agonist effects on NAc neurons, NAc/PFC cocultures were pretreated for $20 \mathrm{~min}$ with media or the protein synthesis inhibitor anisomycin $(40 \mu \mathrm{M})$, followed by incubation with the $\mathrm{D}_{1}$-like agonist SKF 81297 ( $\left.1 \mu \mathrm{M}\right)$ for 15 min. Pretreatment with anisomycin did not affect basal levels of GluR1 cell surface insertion nor the increased GluR1 insertion induced by SKF 81297 (supplemental Fig. 2 A, available at www.jneurosci.org as supplemental material). As a positive control, we demonstrated that this anisomycin concentration was sufficient to inhibit BDNF-induced translation of the immediate early gene Arc (supplemental Fig. $2 B$, available at www.jneurosci.org as supplemental material). This result and others (Karachot et al., 2001) indicate that our anisomycin protocol is sufficient to inhibit protein synthesis. Thus, the new GluR1 surface expression induced by $\mathrm{D}_{1}$-like receptor activation is attributable to the insertion of preexisting AMPARs rather than the synthesis of new receptors. We similarly reported that brief $\mathrm{D}_{1}$-like agonist exposure increased GluR1 cell surface insertion in hippocampal neurons through a mechanism that was independent of protein synthesis (Gao et al., 2006). Possible explanations for different outcomes in our experiments, compared with results of Smith et al. (2005), include differences in $\mathrm{D}_{1}$-like agonist treatment (drug, concentration, and timing of some experiments) and higher cell density in their cultures, perhaps leading to differences in the ongoing level of synaptic transmission. Together, these results suggest that activation of the $\mathrm{D}_{1}$-like receptor-PKA pathway may increase AMPAR levels through both protein synthesisdependent and -independent mechanisms. Further supporting a protein synthesis-independent mechanism, brief PKA activation increased surface GluR1 expression but not total GluR1 protein in cortical cultures (Man et al., 2007).
The $\mathrm{D}_{1}$-like receptor agonist SKF 81297 facilitates glycineinduced synaptic incorporation of GluR1 in medium spiny neurons

Considerable evidence suggests that PKA-mediated increases in GluR1 surface expression prime GluR1 for synaptic delivery (Esteban et al., 2003; Sun et al., 2005; Gao et al., 2006; Oh et al., 2006; Man et al., 2007). We thus hypothesized that $\mathrm{D}_{1}$-like receptors, by increasing extrasynaptic levels of GluR1, would facilitate GluR1 synaptic delivery in response to subsequent NMDA receptor (NMDAR) activation. To test this hypothesis, we adapted an assay developed by Lu et al. (2001) in which glycine, an obligatory coagonist at the NMDAR, is added briefly to cultured neurons in a bathing solution containing TTX. TTX reduces glutamate release to allow the release of only a few quanta of transmitter from each terminal, confining release to the synapse. Under these conditions, glycine selectively potentiates synaptic NMDAR transmission, resulting in synaptic incorporation of GluR1-containing AMPARs and LTP (Lu et al., 2001). In our study, we used a subthreshold concentration of glycine $(1 \mu \mathrm{M})$ that does not produce significant AMPAR incorporation on its own (Sun et al., 2005; Gao et al., 2006). After preblocking, NAc/PFC cocultures were pretreated with the $\mathrm{D}_{1}$-like agonist SKF $81297(1 \mu \mathrm{M}, 15$ $\mathrm{min})$, rinsed, incubated with the subthreshold concentration of glycine ( $1 \mu \mathrm{M}, 3 \mathrm{~min}$ ), rinsed, transferred to glycine-free bathing solution for $15 \mathrm{~min}$, and then stained for GluR1 and synaptobrevin (SKF $\rightarrow$ Gly group). Other experimental groups were treated with SKF only, glycine only, or glycine and SKF in the reverse order (Gly $\rightarrow$ SKF). Effects on GluR1 surface expression and synaptic incorporation are shown in Figure $4, A$ and $B$, respectively, with representative images shown in Figure $4 C$. As expected, SKF increased insertion of new GluR1 onto the cell surface, whether alone or in combination with glycine (Fig. 4A), whereas neither glycine nor SKF alone was sufficient to significantly increase GluR1 synaptic incorporation (Fig. 4B). However, cells treated with SKF followed by glycine showed a significant increase in GluR1 synaptic incorporation (Fig. 4B). A trend toward an increase was observed when drugs were applied in the reverse order (Gly $\rightarrow$ SKF group) or after SKF alone. Analysis of synaptic and nonsynaptic GluR1 area confirmed the above findings (data not shown). To confirm that glycine was working via NMDARs, we demonstrated that inclusion of the NMDAR antagonist APV in the bath significantly decreased GluR1 synaptic delivery in cells treated with SKF and glycine but did not prevent SKF from increasing GluR1 cell surface insertion (supplemental Fig. $3 A, B$, available at www.jneurosci.org as supplemental material). This observation is consistent with the fact that LTP induction in NAc neurons requires NMDAR stimulation (Pennartz et al., 1993; Kombian and Malenka, 1994). Overall, our results indicate that $\mathrm{D}_{1}$-like and NMDA receptors work cooperatively to induce GluR1 synaptic incorporation.

The above findings support our hypothesis that PKAmediated increases in the extrasynaptic GluR1 pool facilitate NMDAR-dependent synaptic GluR1 delivery. However, other mechanisms could also contribute to this facilitating effect. One possibility is that PKA activation induced by SKF treatment enhances the response of NMDARs to glycine, and this enables a subthreshold concentration of glycine to produce GluR1 synaptic incorporation. Supporting this possibility, $\mathrm{D}_{1}$-like receptors enhance NMDAR transmission through several mechanisms that include direct physical interactions and second-messengermediated effects on NMDAR currents and trafficking (for review, see Cepeda and Levine, 2006). We focused on a series of studies in dorsal striatal tissue showing that $\mathrm{D}_{1}$-like receptor stimulation 
A

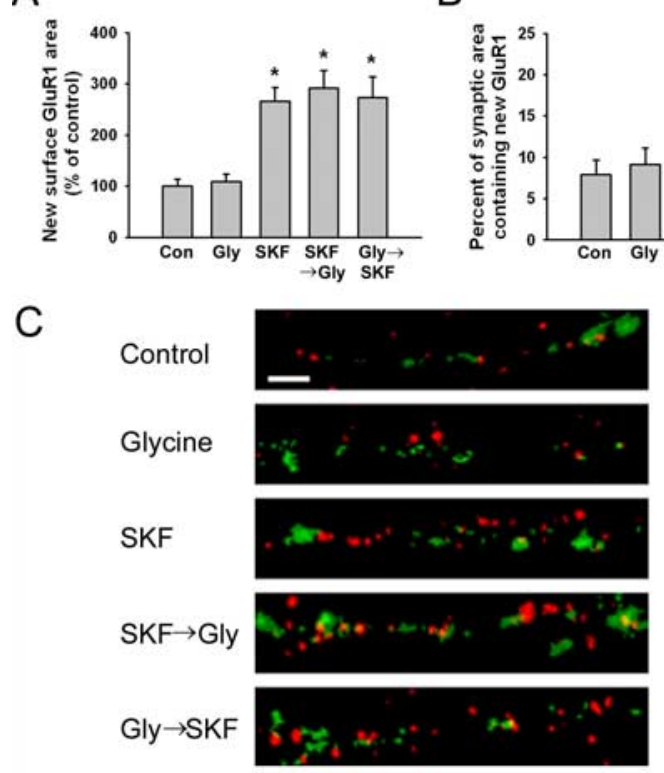

Figure 4. The $D_{1}$-like receptor agonist SKF 81297 facilitated NMDAR-dependent synaptic incorporation of GluR1 in medium spiny NAc neurons. We used a subthreshold concentration of the NMDAR coagonist glycine $(1 \mu \mathrm{m})$ that on its own does not induce GluR1 synaptic delivery. $A$, SKF significantly increased GluR1 insertion onto the cell surface whether added before or after glycine (Gly). Cultures in the SKF $81297 \rightarrow$ glycine group were treated 15 min with $1 \mu \mathrm{M}$ SKF, rinsed, and treated 3 min with $1 \mu \mathrm{m}$ glycine. Cultures in the glycine $\rightarrow$ SKF group were treated in the reverse order. Results are presented as the mean area of GluR1 puncta, normalized to controls (Con; $n=19-25$; Dunn's test, ${ }^{*} p<0.05$ compared with control group and $1 \mu \mathrm{M}$ glycine group). $\boldsymbol{B}$, SKF significantly increased GluR1 synaptic incorporation when added before glycine. The SKF, glycine, and glycine $\rightarrow$ SKF groups did not differ significantly from controls. Results are presented as the percentage of synaptic area containing new GluR1 [(SB + GluR1 area)/total SB area $\times 100]$ ( $n=19-25$; Dunn's test, ${ }^{*} p<0.05$ compared with control group). C, Examples of colocalization of GluR1 with SB on processes of control neurons and neurons treated with glycine (1 $\mu \mathrm{M}, 3 \mathrm{~min})$, SKF (1 $\mu \mathrm{M}, 15 \mathrm{~min})$, SKF $\rightarrow$ glycine, and glycine $\rightarrow$ SKF. GluR1 was detected with Cy3 secondary antibody (red), whereas SB was detected with Alexa 350 (original color was blue; green pseudocolor is used for clarity). Scale bar, $2.5 \mu \mathrm{m}$.

increased NMDAR surface expression (Dunah and Standaert, 2001; Dunah et al., 2004; Hallett et al., 2006). To determine whether a similar effect occurred in NAc/PFC cocultures, we used a $\mathrm{BS}^{3}$ protein crosslinking assay that has been used to study glutamate receptor trafficking in dissociated cultures (Hall and Soderling, 1997a,b; Hall et al., 1997; Archibald et al., 1998). No NR1 antibody exists that is suitable for this assay (or for live-cell labeling), so we focused on NR2A and NR2B. We found no significant changes in surface, intracellular, or total levels of either subunit after treatment with SKF 81297 (1 $\mu \mathrm{M}, 15 \mathrm{~min})$ (NR2A: surface, $115 \pm 19.1$; intracellular, $85.4 \pm 14.8$; total, $99.9 \pm 13.8$; NR2B: surface, $102.8 \pm 20.1$; intracellular, $91.8 \pm 5.4$; total, $97.3 \pm 9.9$; all values expressed as percentage of vehicle treated cultures, $n=7-11$ per group). As a positive control, we have used the same assay to demonstrate increased NR2B surface expression after $\mathrm{D}_{1}$-like agonist treatment of PFC cultures (C. Gao and M. E. Wolf, unpublished findings). Differences between our results in NAc/PFC cocultures and those obtained in striatal tissue (Dunah and Standaert, 2001; Dunah et al., 2004; Hallett et al., 2006) could reflect use of a different $D_{1}$-like agonist and concentration in striatal tissue (SKF 82958 [( \pm )-6-chloro-7,8dihydroxy-3-allyl-1-phenyl-2,3,4,5-tetrahydro- $1 \mathrm{H}$-3-benzazepine hydrobromide]; $50 \mu \mathrm{M}$ ), the use of brain tissue rather than cultured neurons, and differences between ventral (accumbens) and dorsal striatum. Although the quantity of surface NMDARs is not altered by $\mathrm{D}_{1}$-like receptor stimulation in NAc/PFC cocultures, it remains possible that NMDAR function is enhanced by the $\mathrm{D}_{1}$-like receptor-PKA pathway and that this contributes to facilitation of glycine action (see Discussion).

\section{Repeated DA treatment decreases $D_{1}$ receptor surface expression in NAc/PFC cocultures}

One goal of this study was to use primary cultures to obtain a better understanding of how AMPAR trafficking in NAc neurons may be altered by repeated exposure to cocaine. We could not use cocaine in our studies, because it acts by blocking the DA transporter on DA nerve terminals, and our cultures do not contain DA neurons. Therefore, we investigated the effect of repeated treatment with DA itself on AMPAR trafficking in NAc/PFC cocultures. Cocultures were treated with either vehicle (control) or DA ( $1 \mu \mathrm{M}, 30 \mathrm{~min}$ ) on days 7,9 , and 11 in culture. Four days after discontinuing repeated treatment (day 15), cells were "challenged" with vehicle or SKF 81297 (1 $\mu \mathrm{M}$, $15 \mathrm{~min}$ ). SKF significantly increased GluR1 insertion onto the cell surface in vehicle-treated cultures, although it failed to do so after repeated DA treatment (Fig. 5A). Thus, repeated DA treatment eliminated the ability of $\mathrm{D}_{1}$-like receptors to regulate AMPAR trafficking.

We ruled out toxic effects of DA as an explanation for refractoriness to the $\mathrm{D}_{1}$-like agonist by showing that repeated $\mathrm{DA}$ treatment had no effect on cell viability (control, $91.5 \pm 2.8 \%$; DA, $88.9 \pm 2.0 \%$; $t$ test, $p>0.05$; assessed with Live/Dead/Viability/ Cytotoxicity Assay; Invitrogen). Then we determined whether the effect of repeated DA treatment was DA receptor-mediated by applying DA together with the $\mathrm{D}_{1}$-like receptor antagonist $\mathrm{SCH}$ 23390 and the $\mathrm{D}_{2}$-like receptor antagonist raclopride on days 7, 9, and 11. Under these conditions, SKF retained its ability to increase GluR1 surface expression on day 15, demonstrating that repeated DA treatment eliminated the $\mathrm{D}_{1}$-like agonist response through a mechanism requiring DA receptor stimulation (supplemental Fig. 4, available at www.jneurosci.org as supplemental material).

We hypothesized that cells become refractory to SKF 81297 because repeated $D_{1}$ receptor stimulation leads to $D_{1}$ receptor internalization. To test this, NAc/PFC cocultures were treated repeatedly with vehicle or DA on days 7,9 , and 11 , and $\mathrm{D}_{1}$ receptor surface expression was measured on day 15 using antibody to an extracellular epitope of the $D_{1}$ receptor. Repeated DA treatment significantly decreased $D_{1}$ receptor surface expression compared with the control group (Fig. $5 B, C$ ), suggesting that $D_{1}$ receptors internalize during repeated $D A$ treatment and that $D_{1}$ receptor surface expression remains low even $4 \mathrm{~d}$ after the last $\mathrm{DA}$ exposure. Interestingly, total $\mathrm{D}_{1}$ receptor protein levels, determined by Western blotting, were significantly increased on day 15 after repeated DA treatment (control, $100 \pm 13 ; \mathrm{DA}, 263 \pm 75$; data expressed as percentage of vehicle-treated cultures; $t$ test, $p<0.05 ; n=6$ ), despite the fact that cell surface $\mathrm{D}_{1}$ receptor expression was reduced (see Discussion). Refractoriness to the $\mathrm{D}_{1}$-like agonist could also reflect impaired PKA regulation of GluR1 trafficking. However, this possibility was eliminated by demonstrating that repeated DA treatment did not influence the ability of SpcAMPS, a direct PKA activator, to increase GluR1 surface expression (Fig. 5A). This experiment also showed that refractoriness to the $D_{1}$-like agonist was not attributable to a ceiling level of GluR1 surface expression. 
A

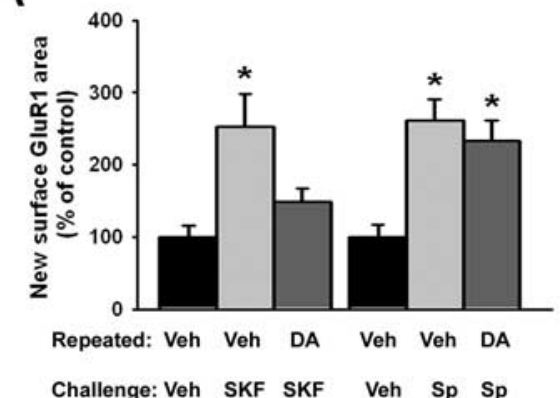

C

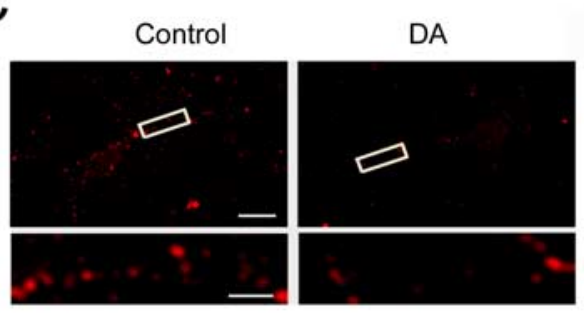

E

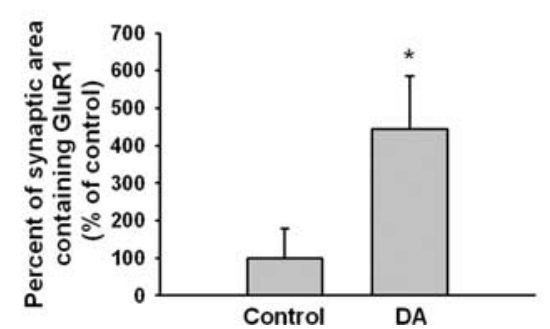

B

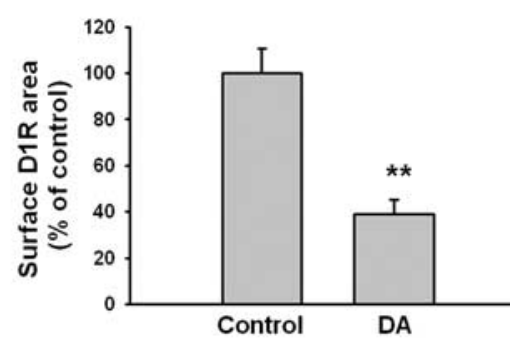

D

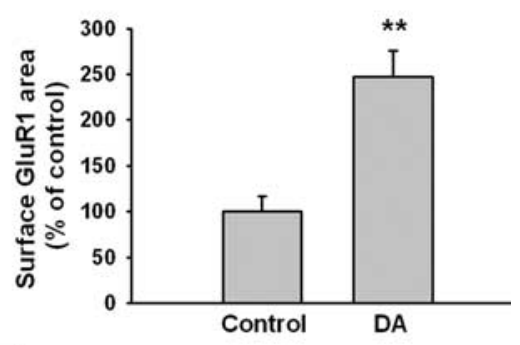

$\mathrm{F}$

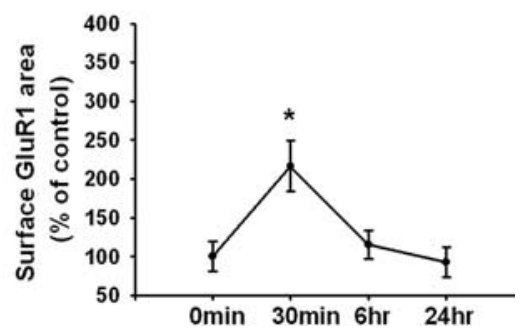

Figure 5. Repeated DA treatment altered the regulation of DA and AMPAR surface expression on medium spiny NAc neurons. A-E compare two pretreatment conditions, termed Control and DA. Control, NAc/PFC cocultures were treated with vehicle on days $7,9$, and 11 in culture. DA, NAC/PFC cocultures were treated with DA (1 $\mu \mathrm{M}, 30 \mathrm{~min})$ on days 7, 9, and 11. A, 0n day 15, control and DA-treated cultures were challenged with vehicle (Veh), SKF 81297 (1 $\mu \mathrm{M}, 15 \mathrm{~min}$ ), or SpcAMPS (Sp; $10 \mu \mathrm{M}, 15 \mathrm{~min})$. In control cultures, SKF and SpCAMPS significantly increased the area of newly inserted GluR1 on the cell surface. After repeated DA treatment, $D_{1}$-like receptor stimulation was no longer able to increase GluR1 cell surface insertion, whereas SpcAMPS maintained its ability to increase GluR1 insertion. All data are normalized to control group $\left(n=17-31 ; t\right.$ test, ${ }^{*} p<0.05$ compared with vehicle + vehicle group). $\boldsymbol{B}$, For this and $\boldsymbol{C}-\boldsymbol{E}$, cells were treated as described in $\boldsymbol{A}$ except that no vehicle or SKF 81297 challenge was administered on day 15 . $\boldsymbol{B}$ shows that $D_{1}$ receptor surface expression was significantly decreased in the repeated DA group on day 15 ( $n=19-23 ; t$ test, ${ }^{* *} p<0.01$ compared with vehicle-treated group). C, Representative images of $D_{1}$ receptor surface expression on day 15 after repeated vehicle or DA treatment. Scale bars, $10 \mu \mathrm{m}$ for large panels. Higher-power views of selected areas (white squares) are also shown (scale bar, $2 \mu \mathrm{m}$ ). D, Quantification of GluR1 surface expression on day 15 after repeated vehicle or DA treatment ( $n=22-27 ; t$ test, ${ }^{* *} p<0.01$ compared with vehicle treated group). $E$, Quantification of the percentage of synaptic area containing GluR1 on day 15 after repeated vehicle or DA treatment $\left(n=22-27 ; t\right.$ test, ${ }^{*} p<0.05$ compared with vehicle treated group). $\boldsymbol{F}$, Time course of GluR1 surface expression after a single DA treatment ( $1 \mu \mathrm{m}, 30 \mathrm{~min}$ ) on day 11 in vitro ( $n=17-25$ for each time-point; Dunn's test, ${ }^{*} p<0.05$ compared with 0 min group).

\section{Repeated DA treatment increases GluR1 surface and synaptic expression in NAc/PFC cocultures}

We also measured GluR1 surface expression after repeated DA treatment and found that both surface and synaptic GluR1 levels were increased on day 15 (Fig. $5 D, E$ ). In light of the ability of $\mathrm{D}_{1}$-like receptors to acutely increase GluR1 surface expression (Fig. $3 A, B$ ), we considered the possibility that GluR1 upregulation after repeated DA treatment was a direct and persistent effect of the final DA treatment on day 11 (although if this was the case, an increase in synaptic GluR1 would not have been expected). To evaluate this possibility, we examined the time course of GluR1 surface expression after a single DA exposure on day 11. GluR1 surface expression was significantly increased immediately after
DA treatment ( $1 \mu \mathrm{M}, 30 \mathrm{~min})$ but returned to basal levels after $6 \mathrm{~h}$ and remained at basal levels $24 \mathrm{~h}$ after DA treatment (Fig. $5 F)$. This indicates that the enhanced GluR1 surface expression induced by a single exposure to DA is transient, and thus the persistently enhanced GluR1 surface expression observed in Figure $5 D$ is the consequence of repeated DA treatment. A final conclusion that can be drawn from Figure $5 F$ is that DA has the same effect on GluR1 surface expression as the $\mathrm{D}_{1}$-like agonist SKF 81297 (both produce an increase), establishing that effects we observed with a $\mathrm{D}_{1}$-like agonist are relevant to endogenous DA transmission.

The observed increase in GluR1 surface and synaptic expression after repeated DA treatment is of interest because AMPAR surface expression is also increased in the NAc after in vivo cocaine treatment (see Discussion). To investigate mechanisms that might underlie the effects of repeated DA treatment, NAc/PFC cocultures were treated repeatedly with vehicle or DA as described above and harvested on day 15 (without challenge) for Western blot analysis of three signaling pathways important for both addiction and regulation of AMPAR trafficking: PKA, ERK, and CaMKII. Measuring signaling pathway activation $4 \mathrm{~d}$ after the last DA exposure is justified based on evidence that repeated in vivo administration of psychomotor stimulants can produce changes in protein kinase activity that persist days to weeks after discontinuing drug exposure (Gnegy, 2000; Hope et al., 2005; Boudreau et al., 2007).

PKA phosphorylation of GluR1 is associated with AMPAR surface expression (Ehlers, 2000; Chao et al., 2002a,b; Esteban et al., 2003; Lee et al., 2003a; Lu et al., 2003; Oh et al., 2006; Man et al., 2007). We assessed the overall level of PKA phosphorylation using an antibody that recognizes phosphorylated PKA substrates (see Materials and Methods). We also examined GluR1 phosphorylation at the PKA site (Ser845) using a phospho-specific antibody. Repeated DA treatment failed to alter the overall level of PKA phosphorylation or the ratio of P-845/total GluR1 (Fig. $6 A, B)$. Total GluR1 protein was unchanged (Fig. $6 B$ ). We also measured GluR1 phosphorylation at Ser831, a site phosphorylated by CaMKII and PKC (Roche et al., 1996; Barria et al., 1997; Mammen et al., 1997). Phosphorylation at Ser831 potentiates AMPAR transmission by increasing single-channel conductance (Derkach et al., 1999) but is not required for AMPAR synaptic incorporation (Hayashi et al., 2000). As with Ser845, we found no significant effect of repeated DA treatment (Fig. 6B). However, these negative results should be interpreted with caution, because we may have missed effects confined to a particular cellular compartment, such as the postsynaptic density. We did not examine 


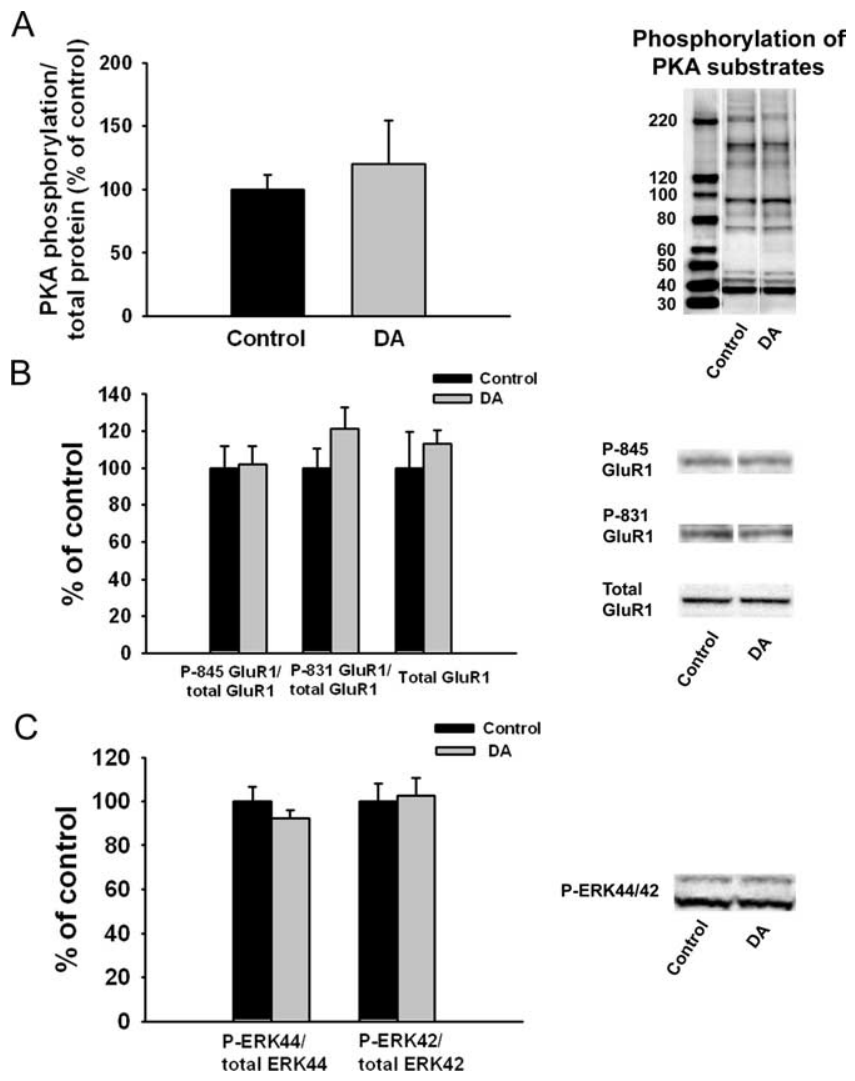

Figure 6. Repeated DA treatment did not alter phosphorylation of PKA substrates, phosphorylation of ERK, or phosphorylation of GluR1 at Ser845 or Ser831. NAc/PFC cocultures were harvested for Western blotting on day 15 after repeated vehicle or DA treatment. Representative blots are shown for all experiments. $\boldsymbol{A}$, PKA phosphorylation was measured using an antibody that recognizes the phosphorylated PKA consensus sequence (see Materials and Methods). Data are normalized to total protein in the lane and presented as percentage of the control group ( $n=6 ; t$ test, $p>0.05$ ). $\boldsymbol{B}$, GluR1 phosphorylation and total GluR1 expression. Phosphospecific antibodies were used to determine the ratio of P-845 GluR1/total GluR1 and P-831 GluR1/total GluR1. Data are presented as percentage of the control group $(n=6 ; t$ test, $p>$ 0.05). C, ERK44/42 activation was measured as the ratios of P-ERK44/total ERK44 and P-ERK42/ total ERK42. Data are presented as percentage of the control group $(n=6 ; t$ test, $p>0.05)$.

Ser818, a PKC phosphorylation site on GluR1 implicated in AMPAR synaptic incorporation during hippocampal LTP (Boehm et al., 2006).

CaMKII and ERK are required for AMPAR synaptic delivery during hippocampal LTP (Hayashi et al., 2000; Zhu et al., 2002), so we measured their activation state after repeated DA treatment by using Western blotting to assess phosphorylation of CaMKII (P-CaMKII/total CaMKII) and ERK44/42 (P-ERK44/total ERK44 and P-ERK42/total ERK42). Although repeated DA treatment had no effect on ERK phosphorylation (Fig. 6C), it significantly increased phosphorylation of CaMKII (Fig. 7A). Total expression of CaMKII and ERK44/42 remained unchanged after repeated DA treatment (data not shown). In contrast, acute DA treatment failed to produce activation of CaMKII (Fig. 7A). Activation of CaMKII after repeated but not acute DA treatment may explain why only repeated DA treatment is sufficient to increase synaptic GluR1 levels. The observation that GluR1 Ser831 phosphorylation is not increased after repeated DA treatment (Fig. 6B) despite activation of CaMKII (Fig. 7A) is consistent with similar results in hippocampal neurons (no increase in GluR1 Ser831 phosphorylation despite activation of CaMKII) that were attributed to different compartmentalization of
CaMKII and GluR1 in the postsynaptic density (Tsui and Malenka, 2006).

To determine whether CaMKII activation was required for increased GluR1 surface expression after repeated DA treatment, the CaMKII inhibitor KN-93 (N-[2-[N-(4-chlorocinnamyl)- $N$ methylaminomethyl]phenyl]-N-(2-hydroxyethyl)-4-methoxybenzenesulfonamide phosphate salt) (Sumi et al., 1991) was added to the media immediately after the last DA treatment on day 11 and washed out just before GluR1 immunostaining on day 15. KN-93 blocked the increase in GluR1 surface and synaptic expression produced by repeated DA treatment (Fig. $7 B, C$ ). KN-93 treatment had no effect on cell viability (control, $88.3 \pm 2.0 \%$; KN-93, $87.3 \pm 1.4 \%$; $t$ test, $p>0.05$; assessed with Live/Dead/Viability/Cytotoxicity Assay; Invitrogen). These results suggest that activation of CaMKII after repeated DA treatment is required for the observed increase in GluR1 surface expression.

The question of how repeated DA treatment activates CaMKII is intriguing. As noted above, $\mathrm{D}_{1}$-like receptors can increase surface expression of NMDARs in striatal tissue (Dunah and Standaert, 2001; Dunah et al., 2004; Hallett et al., 2006), which might lead to increased $\mathrm{Ca}^{2+}$ signaling and activation of CaMKII. Although we did not observe an increase in NMDAR surface expression after acute DA treatment (above), we tested the effect of repeated DA treatment on NR2A and NR2B surface expression using a $\mathrm{BS}^{3}$ protein crosslinking assay. We found no significant differences in surface, intracellular, or total protein expression of either subunit after repeated DA treatment (NR2A: surface, $96.7 \pm 15.0$; intracellular, $111.2 \pm 12.6$; total, 102.9 \pm 7.3; NR2B: surface, $98.7 \pm 8.9$; intracellular, $105.7 \pm 7.4$; total, $101.9 \pm 7.3$; all values expressed as percentage of vehicle-treated cultures; $n=$ 6-7 per group). It remains possible that $\mathrm{D}_{1}$-like receptor activation enhances NMDAR transmission or $\mathrm{Ca}^{2+}$ signaling through other mechanisms, contributing to CaMKII activation (see Discussion).

\section{Discussion}

\section{Acute $\mathrm{D}_{1}$-like receptor modulation of AMPAR trafficking in} NAc neurons

We used NAc/PFC cocultures to study dopaminergic regulation of excitatory synapses on medium spiny NAc neurons. We found that brief incubation with the $\mathrm{D}_{1}$-like agonist SKF $81297(1 \mu \mathrm{M}$, $15 \mathrm{~min}$ ) increased AMPAR insertion on the extrasynaptic cell surface. This required PKA activity but not protein synthesis. The same $D_{1}$-like agonist treatment facilitated AMPAR synaptic delivery in response to subsequent activation of synaptic NMDARs with glycine. We hypothesize that this facilitation occurred because $\mathrm{D}_{1}$-like agonist treatment increased the size of the extrasynaptic GluR1 pool, thereby facilitating GluR1 translocation into the synapse. This hypothesis is consistent with a two-step model for AMPAR synaptic incorporation (surface insertion followed by synaptic incorporation) (Passafaro et al., 2001) and with evidence that PKA phosphorylation of GluR1 increases its surface insertion and thereby primes its synaptic delivery (Esteban et al., 2003; Sun et al., 2005; Gao et al., 2006; Oh et al., 2006; Man et al., 2007).

An alternative explanation for facilitation of GluR1 synaptic delivery is that $\mathrm{D}_{1}$-like receptor stimulation potentiates NMDAR transmission. This can occur through many mechanisms (Cepeda and Levine, 2006), including increased NMDAR surface expression (Dunah and Standaert, 2001). We tested this possibility but failed to detect increased NMDAR surface expression after $\mathrm{D}_{1}$-like receptor stimulation. Future studies could determine whether other mechanisms linking the $\mathrm{D}_{1}$ receptor-PKA path- 
A

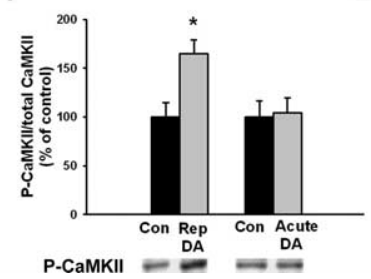

B

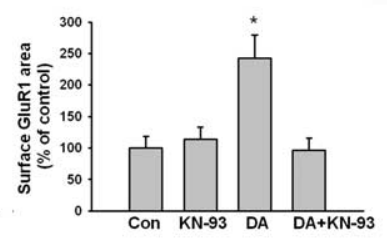

Figure 7. CaMKII activation was increased after repeated DA treatment, and CaMKII activity was required for increased GluR1 surface expression after repeated DA treatment. $\boldsymbol{A}$, Repeated (Rep) DA treatment increased CaMKII activation but acute DA treatment did not. NAc/PFC cocultures were harvested for Western blotting on day 15 after repeated treatment (days 7, 9, and 11; $30 \mathrm{~min} / \mathrm{d}$ ) with vehicle or DA $(1 \mu \mathrm{M})$ or after acute treatment ( $30 \mathrm{~min}$ ) with vehicle or DA ( $1 \mu \mathrm{M})$. CaMKIl activation was measured as the ratio of P-CaMKII/total CaMKII. Data are presented as percentage of the control group (Con; $n=6, t$ test; ${ }^{*} p<0.05$ compared with control group). Representative blots are shown. Data shown are for $\alpha$ CaMKII but we also examined $\beta$ CaMKII and found no effect of either acute or repeated DA treatment (data not shown). $\boldsymbol{B}$, The CaMKII inhibitor KN-93 blocked the increased GluR1 surface expression produced by repeated DA treatment. NAC/PFC cocultures were treated repeatedly with vehicle or DA as described above. After the last DA application on day 11, KN-93 (5 $\mu \mathrm{m})$ was added to the media until day 15 , when it was washed out before immunostaining for surface GluR1. Results are presented as the mean area of GluR1 puncta, normalized to controls ( $n=24-29$; Dunn's test, ${ }^{*} p<0.05$ compared with control group, KN-93 group, and repeated DA + KN-93 group). C, The CaMKII inhibitor KN-93 blocked the increased synaptic GluR1 expression produced by repeated DA treatment. Results are presented as the percentage of synaptic area containing GluR1, normalized to the control group ( $n=20-27$; Dunn's test, ${ }^{*} p<0.05$ compared with control group).

way to NMDAR transmission contribute to $\mathrm{D}_{1}$-like receptor facilitation of GluR1 synaptic incorporation. For example, the $\mathrm{D}_{1}$ like receptor-PKA pathway enhances NMDAR currents in striatal neurons by modulating L-type $\mathrm{Ca}^{2+}$ channels (Cepeda and Levine, 2006) and PKA increases $\mathrm{Ca}^{2+}$ conductance of NMDARs in hippocampal neurons (Skeberdis et al., 2006). Another possible explanation is suggested by reports that PKA activity increases presynaptic release probability at some glutamate synapses (Evans et al., 2001). Arguing against this is electrophysiological evidence that $\mathrm{D}_{1}$-like receptor activation decreases glutamate release from terminals in the NAc (Pennartz et al., 1992; Nicola et al., 1996; Nicola and Malenka, 1997).

Regardless of the mechanism, our results suggest that $D_{1}$-like and NMDA receptors work cooperatively to promote AMPAR synaptic delivery. This may underlie the requirement for coordinated $\mathrm{D}_{1}$-like and NMDA receptor stimulation in the NAc for reward-related learning (Kelley et al., 1997; Smith-Roe and Kelley, 2000; Beninger and Gerdjikov, 2004; Dalley et al., 2005; Hernandez et al., 2005; Heusner and Palmiter, 2005).

\section{$D_{1}$-like receptor regulation of AMPAR trafficking is lost after repeated DA treatment}

Repeated cocaine exposure alters $\mathrm{D}_{1}$-like receptor sensitivity and PKA signaling (White and Kalivas, 1998; Hope et al., 2005), suggesting that $\mathrm{D}_{1}$-like receptor regulation of AMPAR trafficking in NAc neurons may also be altered. To test this, NAc/PFC cultures were treated repeatedly with DA (days 7, 9, and 11 in vitro). Four days later (day 15), cultures were incubated with the $\mathrm{D}_{1}$-like agonist SKF 81297 ( $1 \mu \mathrm{M}, 15 \mathrm{~min})$. Although this $\mathrm{D}_{1}$-like agonist treatment increased GluR1 surface expression in control cultures (above), it failed to do so after repeated DA treatment. If refractoriness similarly develops after repeated in vivo cocaine exposure, one consequence could be loss of the ability of DA to facilitate plasticity in the NAc during cocaine withdrawal.

To determine whether refractoriness reflects $D_{1}$ receptor internalization, we measured $D_{1}$ receptor surface expression on day 15 after repeated DA or vehicle treatment. Control cultures showed robust $\mathrm{D}_{1}$ receptor surface expression at extrasynaptic sites on medium spiny neurons, but this was significantly decreased after repeated DA treatment. $D_{1}$ receptor internalization changed (Stanwood and Levitt, 2007).

\section{GluR1 surface expression increases after repeated DA treatment: an in vitro model for cocaine-induced increases in AMPAR surface expression?}

GluR1 surface expression was significantly increased after repeated DA treatment. This was attributable to repeated DA treatment, not to lingering effects of the final DA exposure. This is reminiscent of results obtained in rats treated repeatedly with cocaine to produce behavioral sensitization, a persistent enhancement of behavioral responses mediated by plasticity in addiction-related neuronal circuits (Boudreau and Wolf, 2005, 2006; Boudreau et al., 2007). Using a protein crosslinking assay, we showed that cocaine-sensitized rats exhibited increased cell surface levels of GluR1/2-containing AMPARs in the NAc after 1-3 weeks of withdrawal from cocaine. On withdrawal day 1 , rats expressed locomotor sensitization but surface AMPAR levels were normal, indicating that AMPAR upregulation does not underlie locomotor sensitization. Rather, we proposed that increased AMPAR surface expression increases the responsiveness of NAc neurons to cortical and limbic glutamate inputs that trigger drug seeking and thereby contributes to sensitization of the incentive-motivational effects of cocaine (Boudreau and Wolf, 2005). A sensitization-related increase in AMPAR synaptic transmission in the NAc has also been detected electrophysiologically (Kourrich et al., 2007).

We investigated possible mechanisms of increased GluR1 surface expression after repeated DA treatment by measuring activation of CaMKII, ERK, and PKA in NAc/PFC cocultures treated repeatedly with DA or vehicle and harvested $4 \mathrm{~d}$ later (day 15). We focused on CaMKII, ERK, and PKA based on their roles in AMPAR synaptic targeting (Zhu et al., 2002; Esteban et al., 2003; Sun et al., 2005; Oh et al., 2006) and addiction (Gnegy, 2000; Hope et al., 2005; Lu et al., 2006). ERK phosphorylation and phosphorylation of PKA substrates were not altered by repeated DA treatment. It should be noted that our negative findings for PKA were based on averaging signals from many PKAphosphorylated substrates. Although this approach has the advantage of not relying on a single protein as an index of PKA activity, it could overlook specific effects on relevant substrates. 
In contrast, repeated DA treatment produced a significant increase in CaMKII phosphorylation at Thr286. CaMKII activation is necessary to drive AMPARs into synapses during hippocampal LTP (Hayashi et al., 2000), so we tested the hypothesis that CaMKII activation is necessary for increased GluR1 surface expression after repeated DA treatment. We found that GluR1 upregulation was prevented by inhibiting CaMKII during the $4 \mathrm{~d}$ period after discontinuing DA treatment. These results suggest that CaMKII is activated after repeated DA treatment and that this is necessary for GluR1 upregulation. Furthermore, they strengthen the idea that repeated DA treatment of NAc/PFC cocultures provides a model for repeated cocaine treatment in vivo. In addition to the fact that both treatments produce AMPAR upregulation (above), we observed CaMKII activation in the NAc at the earliest withdrawal time from cocaine (day 7 ) that AMPAR surface expression is increased (A. C. Boudreau and M. E. Wolf, unpublished findings). Other in vivo studies provide additional support for the idea that CaMKII is activated in the NAc during cocaine withdrawal and contributes to increased AMPAR transmission and other adaptations (Pierce and Kalivas, 1997; Pierce et al., 1998; Singer et al., 2006).

It is unclear how repeated DA treatment activates CaMKII, although DA receptors are linked to several signaling pathways that regulate $\mathrm{Ca}^{2+}$ channels or mobilize intracellular $\mathrm{Ca}^{2+}$ (Nicola et al., 2000; Neve et al., 2004). Once activated, CaMKII may promote AMPAR synaptic incorporation through mechanisms related to those involved in hippocampal LTP, although the CaMKII substrate important in AMPAR insertion during LTP is unknown. One possibility is that CaMKII decreases the activity of a synaptic RasGAP, leading to activation of ERK and AMPAR synaptic insertion (Rumbaugh et al., 2006 and references therein), but we did not observe ERK activation after repeated DA treatment. Interestingly, ERK is activated in the NAc of cocaine-sensitized rats (Boudreau et al., 2007), demonstrating that repeated DA treatment does not reproduce all aspects of cocaine withdrawal, as expected. Alternatively, the important CaMKII substrate could be a transmembrane AMPAR regulatory protein (TARP). TARPs are phosphorylated by CaMKII (Tsui and Malenka, 2006), and this may contribute to AMPAR synaptic incorporation during LTP (Tomita et al., 2005).

\section{Conclusions}

In medium spiny NAc neurons cocultured with PFC neurons, acute $\mathrm{D}_{1}$-like receptor stimulation increased extrasynaptic AMPAR levels, facilitating their NMDAR-dependent synaptic incorporation. Repeated DA treatment abolished this response by decreasing $\mathrm{D}_{1}$ receptor surface expression. Repeated DA treatment also increased AMPAR surface expression; this was associated with CaMKII activation and prevented by CaMKII inhibition. These findings, combined with in vivo results, suggest that psychomotor stimulants, by increasing DA levels, may initially facilitate plasticity in the NAc, perhaps contributing to learning of drug-seeking behaviors. After drug withdrawal, this regulatory mechanism may be impaired, but accumbens neurons may be more responsive to glutamate inputs that trigger drug seeking.

\section{References}

Aizman O, Brismar H, Uhlén P, Zettergren E, Levey A, Forssberg H, Greengard P, Aperia A (2000) Anatomical and physiological evidence for D1 and D2 dopamine receptor colocalization in neostriatal neurons. Nat Neurosci 3:226-230.

Archibald K, Perry MJ, Molnár E, Henley JM (1998) Surface expression and metabolic half-life of AMPA receptors in cultured rat cerebellar granule cells. Neuropharmacology 37:1345-1353.
Ariano MA, Sibley DR (1994) Dopamine receptor distribution in the rat CNS: elucidation using anti-peptide antisera directed against D1A and D3 subtypes. Brain Res 649:95-110.

Ariano MA, Stromski CJ, Smyk-Randall EM, Sibley DR (1992) D2 dopamine receptor localization on striatonigral neurons. Neurosci Lett 144:215-220.

Ariano MA, Wang J, Noblett KL, Larson ER, Sibley DR (1997a) Cellular distribution of the rat $\mathrm{D} 1 \mathrm{~B}$ receptor in central nervous system using antireceptor antisera. Brain Res 746:141-150.

Ariano MA, Sortwell CE, Ray M, Altemus KL, Sibley DR, Levine MS (1997b) Agonist-induced morphologic decrease in cellular D1A dopamine receptor staining. Synapse 27:313-321.

Barria A, Derkach V, Soderling T (1997) Identification of the $\mathrm{Ca}^{2+} /$ calmodulin-dependent protein kinase II regulatory phosphorylation site in the alpha-amino-3-hydroxyl-5-methyl-4-isoxazole-propionate-type glutamate receptor. J Biol Chem 272:32727-32730.

Beninger RJ, Gerdjikov T (2004) The role of signaling molecules in rewardrelated incentive learning. Neurotox Res 6:91-104.

Bergson C, Mrzljak L, Smiley JF, Pappy M, Levenson R, Goldman-Rakic PS (1995) Regional, cellular, and subcellular variations in the distribution of $\mathrm{D}_{1}$ and $\mathrm{D}_{5}$ dopamine receptors in primate brain. J Neurosci 15:7821-7836.

Bernard V, Somogyi P, Bolam JP (1997) Cellular, subcellular, and subsynaptic distribution of AMPA-type glutamate receptor subunits in the neostriatum of the rat. J Neurosci 17:819-833.

Bloch B, Bernard V, Dumartin B (2003) “In vivo" intraneuronal trafficking of $\mathrm{G}$ protein coupled receptors in the striatum: regulation by dopaminergic and cholinergic environment. Biol Cell 95:477-488.

Boehm J, Kang MG, Johnson RC, Eesteban J, Huganir RL, Malinow R (2006) Synaptic incorporation of AMPA receptors during LTP is controlled by a PKC phosphorylation site on GluR1. Neuron 51:213-225.

Bossert JM, Ghitza UE, Lu L, Epstein DH, Shaham Y (2005) Neurobiology of relapse to heroin and cocaine seeking: an update and clinical implications. Eur J Pharmacol 526:36-50.

Boudreau AC, Wolf ME (2005) Behavioral sensitization to cocaine is associated with increased AMPA receptor surface expression in the nucleus accumbens. J Neurosci 25:9144-9151.

Boudreau AC, Wolf ME (2006) Dysregulation of signal transduction accompanies AMPA receptor trafficking in the nucleus accumbens during behavioral sensitization to cocaine. Soc Neurosci Abstr 32:394.7.

Boudreau AC, Reimers JM, Milovanovic M, Wolf ME (2007) Cell surface AMPA receptors in the rat nucleus accumbens increase during cocaine withdrawal but internalize upon cocaine challenge in association with altered activation of mitogen-activated protein kinases. J Neurosci 27:10621-10635.

Cepeda C, Levine MS (2006) Where do you think you are going? The NMDA-D1 receptor trap. Sci STKE 333:20.

Chao SZ, Lu W, Lee HK, Huganir RL, Wolf ME (2002a) D1 dopamine receptor stimulation increases GluR1 phosphorylation in postnatal nucleus accumbens cultures. J Neurochem 81:984-992.

Chao SZ, Ariano MA, Peterson DA, Wolf ME (2002b) D1 dopamine receptor stimulation increases GluR1 surface expression in nucleus accumbens neurons. J Neurochem 83:704-712.

Chen Q, Veenman L, Knopp K, Yan Z, Medina L, Song WJ, Surmeier DJ, Reiner A (1998) Evidence for the preferential localization of glutamate receptor-1 subunits of AMPA receptors to the dendritic spines of medium spiny neurons in rat striatum. Neuroscience 83:749-761.

Dalley JW, Laane K, Theobald DE, Armstrong HC, Corlett PR, Chudasama Y, Robbins TW (2005) Time-limited modulation of appetitive Pavlovian memory by D1 and NMDA receptors in the nucleus accumbens. Proc Natl Acad Sci USA 102:6189-6194.

Deng YP, Lei WL, Reiner A (2006) Differential perikaryal localization in rats of D1 and D2 dopamine receptors on striatal projection neuron types identified by retrograde labeling. J Chem Neuroanat 32:101-116.

Derkach V, Barria A, Soderling TR (1999) $\mathrm{Ca}^{2+} /$ calmodulin-kinase II enhances channel conductance of $\alpha$-amino-3-hydroxy-5-methyl-4isoxazolepropionate type glutamate receptors. Proc Natl Acad Sci USA 96:3269-3274.

Deroche-Gamonet V, Belin D, Piazza PV (2004) Evidence for addiction-like behavior in the rat. Science 305:1014-1017.

Dumartin B, Caille I, Gonon F, Bloch B (1998) Internalization of $D_{1}$ dopa- 
mine receptor in stiatal neurons in vivo as evidence of activation by dopamine agonists. J Neurosci 18:1650-1661.

Dunah AW, Standaert DG (2001) Dopamine $\mathrm{D}_{1}$ receptor-dependent trafficking of striatal NMDA receptors to the postsynaptic membrane. J Neurosci 21:5546-5558.

Dunah AW, Sirianni AC, Fienberg AA, Bastia E, Schwarzschild MA, Standaert DG (2004) Dopamine D1-dependent trafficking of striatal N-methylD-aspartate glutamate receptors requires Fyn protein tyrosine kinase but not DARPP-32. Mol Pharmacol 65:121-129.

Ehlers MD (2000) Reinsertion or degradation of AMPA receptors determined by activitiy-dependent endocytic sorting. Neuron 28:511-525.

Esteban JA, Shi SH, Wilson C, Nuriya M, Huganir RL, Malinow R (2003) PKA phosphorylation of AMPA receptor subunits controls synaptic trafficking underlying plasticity. Nat Neurosci 6:136-143.

Evans DI, Jones RSG, Woodhall G (2001) Differential actions of PKA and PKC in the regulation of glutamate release by group III mGluRs in the entorhinal cortex. J Neurophysiol 85:571-579.

Gao C, Sun X, Wolf ME (2006) Activation of D1 dopamine receptors increases surface expression of AMPA receptors and facilitates their synaptic incorporation in cultured hippocampal neurons. J Neurochem 98:1664-1677.

Gerfen CR, Engber TM, Mahan LC, Susel Z, Chase TN, Monsma Jr FJ, Sibley DR (1990) D1 and D2 dopamine receptor-regulated gene expression of striatonigral and striatopallidal neurons. Science 250:1429-1432.

Gnegy ME (2000) $\mathrm{Ca}^{2+} /$ calmodulin signaling in NMDA-induced synaptic plasticity. Crit Rev Neurobiol 14:91-129.

Groenewegen HJ, Wright CI, Beijer AV, Voorn P (1999) Convergence and segregation of ventral striatal inputs and outputs. Ann NY Acad Sci 877:49-63.

Hall RA, Soderling TR (1997a) Differential surface expression and phosphorylation of the N-methyl-D-aspartate receptor subunits NR1 and NR2 in cultured hippocampal neurons. J Biol Chem 272:4135-4140.

Hall RA, Soderling TR (1997b) Quantitation of AMPA receptor surface expression in cultured hippocampal neurons. Neuroscience 78:361-371.

Hall RA, Hansen A, Andersen PH, Soderling TR (1997) Surface expression of the AMPA receptor subunits GluR1, GluR2, and GluR4 in stably transfected baby hamster kidney cells. J Neurochem 68:625-630.

Hallett PJ, Spoelgen R, Hyman BT, Standaert DG, Dunah AW (2006) Dopamine $\mathrm{D}_{1}$ activation potentiates striatal NMDA receptors by tyrosine phosphorylation-dependent subunit trafficking. J Neurosci 26:4690-4700.

Hara Y, Pickel VM (2005) Overlapping intracellular and differential synaptic distributions of dopamine D1 and glutamate N-methyl-D-aspartate receptors in rat nucleus accumbens. J Comp Neurol 492:442-455.

Hayashi Y, Shi SH, Esteban JA, Piccini A, Poncer JC, Malinow R (2000) Driving AMPA receptors into synapses by LTP and CaMKII: requirement for GluR1 and PDZ domain interaction. Science 287:2262-2267.

Hernandez PJ, Andrzejewski ME, Sadeghian K, Panksepp JB, Kelley AE (2005) AMPA/kainate, NMDA, and dopamine D1 receptor function in the nucleus accumbens core: a context-limited role in the encoding and consolidation of instrumental memory. Learn Mem 12:285-295.

Heusner CL, Palmiter RD (2005) Expression of mutant NMDA receptors in dopamine $D_{1}$ receptor-containing cells prevents cocaine sensitization and decreases cocaine preference. J Neurosci 25:6651-6657.

Hope BT, Crombag HS, Jedynak JP, Wise RA (2005) Neuroadaptations of total levels of adenylate cyclase, protein kinase A, tyrosine hydroxylase, cdk5 and neurofilaments in the nucleus accumbens and ventral tegmental area do not correlate with expression of sensitized or tolerant locomotor responses to cocaine. J Neurochem 92:536-545.

Jay TM (2003) Dopamine: a potential substrate for synaptic plasticity and memory mechanisms. Prog Neurobiol 69:375-390.

Karachot L, Shirai Y, Vigot R, Yamamori T, Ito M (2001) Induction of longterm depression in cerebellar Purkinje cells requires a rapidly turned over protein. J Neurophysiol 86:280-289.

Karpa KD, Lidow MS, Pickering MT, Levenson R, Bergson C (1999) $\mathrm{N}$-linked glycosylation is required for plasma membrane localization of D5, but not D1, dopamine receptors in transfected mammalian cells. Mol Pharmacol 56:1071-1078.

Kauer JA, Malenka RC (2007) Synaptic plasticity and addiction. Nat Rev Neurosci 8:844-858.

Kelley AE (1999) Neural integrative activities of nucleus accumbens subregions in relation to learning and motivation. Psychobiology 27:198-213.
Kelley AE (2004) Ventral striatal control of appetitive motivation; role in ingestive behavior and reward-related learning. Neurosci Biobehav Rev 27:765-776.

Kelley AE, Smith-Roe SL, Holahan MR (1997) Response-reinforcement learning is dependent on $\mathrm{N}$-methyl-D-aspartate receptor activation in the nucleus accumbens core. Proc Natl Acad Sci USA 94:12174-12179.

Kennelly PJ, Krebs EG (1991) Consensus sequences as substrate specificity determinants for protein kinases and protein phosphatases. J Biol Chem 266:15555-15558.

Kombian SB, Malenka RC (1994) Simultaneous LTP of non-NMDA- and LTD of NMDA-receptor-mediated responses in the nucleus accumbens. Nature 368:242-246.

Kourrich S, Rothwell PE, Klug JR, Thomas MJ (2007) Cocaine experience controls bidirectional synaptic plasticity in the nucleus accumbens. J Neurosci 27:7921-7928.

Lee H-K, Takamiya K, Han J-S, Man H, Kim C-H, Rumbaugh G, Yu S, Ding L, He C, Petralia RS, Wenthold RJ, Gallagher M, Huganir RL (2003a) Phosphorylation of the AMPA receptor GluR1 subunit is required for synaptic plasticity and retention of spatial memory. Cell 112:631-643.

Lee SP, O’Dowd BF, Rajaram RD, Nguyen T, George SR (2003b) D2 dopamine receptor homodimerization is mediated by multiple sites of interaction, including an intermolecular interaction involving transmembrane domain 4. Biochemistry 42:11023-11031.

Le Moine C, Bloch B (1995) D1 and D2 dopamine receptor gene expression in the rat striatum: sensitive cRNA probes demonstrate prominent segregation of D1 and D2 mRNAs in distinct neuronal populations of the dorsal and ventral striatum. J Comp Neurol 355:418-426.

Le Moine C, Normand E, Bloch B (1991) Phenotypical characterization of the rat striatal neurons expressing the D1 dopamine receptor gene. Proc Natl Acad Sci USA 88:4205-4209.

Lu HD, She W-C, Plas DT, Neumann PE, Janz R, Crair MC (2003) Adenylyl cyclase I regulates AMPA receptor trafficking during mouse cortical "barrel" map development. Nat Neurosci 6:939-947.

Lu L, Koya E, Zhai H, Hope BT, Shaham Y (2006) Role of ERK in cocaine addiction. Trends Neurosci 29:695-703.

Lu W, Man H, Ju W, Trimble WS, MacDonald JF, Wang YT (2001) Activation of synaptic NMDA receptors induces membrane insertion of new AMPA receptors and LTP in cultured hippocampal neurons. Neuron 29:243-254.

Malinow R, Malenka RC (2002) AMPA receptor trafficking and synaptic plasticity. Annu Rev Neurosci 25:103-126.

Mammen AL, Kameyama K, Roche KW, Huganir RL (1997) Phosphorylation of the alpha-amino-3-hydroxy-5-methylisoxazole4-propionic acid receptor GluR1 subunit by calcium/calmodulin-dependent kinase II. J Biol Chem 272:32528-32533.

Man H-Y, Sekine-Aizawa Y, Huganir RL (2007) Regulation of $\alpha$-amino-3hydroxy-5-methyl-4-isoxazolepropionic acid receptor trafficking through PKA phosphorylation of the Glu receptor 1 subunit. Proc Natl Acad Sci USA 104:3579-3584.

Mangiavacchi S, Wolf ME (2004) D1 dopamine receptor stimulation increases the rate of AMPA receptor insertion onto the surface of cultured nucleus accumbens neurons through a pathway dependent on protein kinase A. J Neurochem 88:1261-1271.

Martin-Negrier M, Charron G, Bloch B (2000) Agonist stimulation provokes dendritic and axonal dopamine $\mathrm{D}(1)$ receptor redistribution in primary cultures of striatal neurons. Neuroscience 99:257-266.

Martin-Negrier ML, Charron G, Bloch B (2006) Receptor recycling mediates plasma membrane recovery of dopamine D1 receptors in dendrites and axons after agonist-induced endocytosis in primary cultures of striatal neurons. Synapse 60:194-204.

McVittie LD, Ariano MA, Sibley DR (1991) Characterization of antipeptide antibodies for the localization of $\mathrm{D} 2$ dopamine receptors in rat striatum. Proc Natl Acad Sci USA 88:1441-1445.

Meador-Woodruff JH, Mansour A, Healy DJ, Kuehn R, Zhou QY, Bunzow JR, Akil H, Civelli O, Watson Jr SJ (1991) Comparison of the distributions of D1 and D2 dopamine receptor mRNAs in rat brain. Neuropsychopharmacology 5:231-242.

Meredith GE, Totterdell S (1999) Microcircuits in nucleus accumbens' shell and core involved in cognition and reward. Psychobiology 27:165-186.

Mogenson GJ, Ciriello J, Garland J, Wu M (1987) Ventral pallidum projections to mediodorsal nucleus of the thalamus: an anatomical and electrophysiological investigation in the rat. Brain Res 404:221-230. 
Neve KA, Seamans JK, Trantham-Davidson H (2004) Dopamine receptor signaling. J Recept Signal Transduct Res 24:165-205.

Nicola SM, Malenka RC (1997) Dopamine depresses excitatory and inhibitory synaptic transmission by distinct mechanisms in the nucleus accumbens. J Neurosci 17:5697-5710.

Nicola SM, Kombian SB, Malenka RC (1996) Psychostimulants depress excitatory synaptic transmission in the nucleus accumbens via presynaptic $\mathrm{D}_{1}$-like dopamine receptors. J Neurosci 16:1591-1604.

Nicola SM, Surmeier DJ, Malenka RC (2000) Dopaminergic modulation of neuronal excitability in the stiatum and nucleus accumbens. Annu Rev Neurosci 232:185-215.

Oh MC, Derkach VA, Guire ES, Soderling TR (2006) Extrasynaptic membrane trafficking regulated by GluR1 serine 845 phosphorylation primes AMPA receptors for long-term potentiation. J Biol Chem 281:752-758.

Passafaro M, Piech V, Sheng M (2001) Subunit-specific temporal and spatial patterns of AMPA receptor exocytosis in hippocampal neurons. Nat Neurosci 4:917-926.

Pearson RB, Kemp BE (1991) Protein kinase phosphorylation site sequences and conseusus specificity motifs: tabulations. Methods Enzymol 200:62-81.

Pennartz CM, Dolleman-Van der Weel MJ, Kitai ST, Lopes da Silva FH (1992) Presynaptic dopamine D1 receptors attenuate excitatory and inhibitory limbic inputs to the shell region of the rat nucleus accumbens studied in vitro. J Neurophysiol 67:1325-1334.

Pennartz CM, Ameerun RF, Groenewegen HJ, Lppes da Silva FH (1993) Synaptic plasticity in an in vivo slice preparation of the rat nucleus accumbens. Eur J Neurosci 5:107-117.

Pierce RC, Kalivas PW (1997) Repeated cocaine modifies the mechanism by which amphetamine releases dopamine. J Neurosci 17:3254-3261.

Pierce RC, Quick EA, Reeder DC, Morgan ZR, Kalivas PW (1998) Calciummediated second messengers modulate the expression of behavioral sensitization to cocaine. J Pharmacol Exp Ther 286:1171-1176.

Roche KW, O'Brien RJ, Mammen AL, Bernhardt J, Huganir RL (1996) Characterization of multiple phosphorylation sites on the AMPA receptor GluR1 subunit. Neuron 16:1179-1188.

Rumbaugh G, Adams JP, Kim JH, Huganir RL (2006) SynGAP regulates synaptic strength and mitogen-activated protein kinases in cultured neurons. Proc Natl Acad Sci USA 103:4344-4351.

Schmidt HD, Anderson SM, Famous KR, Kumaresan V, Pierce RC (2005) Anatomy and pharmacology of cocaine priming-induced reinstatement of drug seeking. Eur J Pharmacol 526:65-76.

Segal M, Greeberger V, Korkotian E (2003) Formation of dendritic spines in cultured striatal neurons depends on excitatory afferent activity. Eur J Neurosci 17:2573-2585.

Sesack SR, Carr DB, Omelchenko N, Pinto A (2003) Anatomical substrates for glutamate-dopamine interactions: evidence for specificity of connections and extrasynaptic actions. Ann NY Acad Sci 1003:36-52.
Shi WX, Rayport S (1994) GABA synapses formed in vitro by local axon collaterals of nucleus accumbens neurons. J Neurosci 14:4548-4560.

Singer BF, Loweth J, Neve RL, Carlezon WA, Bayer KU, Vezina P (2006) Viral-mediated overexpression of CaMKII in the NAcc leads to longlasting alterations in glutamatergic transmission. Soc Neurosci Abstr 32:483.6.

Skeberdis VA, Chevaleyre V, Lau CG, Goldberg JH, Pettit DL, Suadicani SO, Lin Y, Bennett MVL, Yuste R, Castillo PE, Zukin RS (2006) Protein kinase A regulates calcium permeability of NMDA receptors. Nat Neurosci 9:501-510.

Smith WB, Starck SR, Roberts RW, Schuman EM (2005) Dopaminergic stimulation of local protein synthesis enhances surface expression of GluR1 and synaptic transmission in hippocampal neurons. Neuron 45:765-779.

Smith-Roe SL, Kelley AE (2000) Coincident activation of NMDA and dopamine $D_{1}$ receptors within the nucleus accumbens core is required for appetitive instrumental learning. J Neurosci 20:7737-7742.

Stanwood GD, Levitt P (2007) Prenatal exposure to cocaine produces unique developmental and long-term adaptive changes in dopamine $\mathrm{D}_{1}$ receptor activity and subcellular distribution. J Neurosci 27:152-157.

Sumi M, Kiuchi K, Ishikawa T, Ishii A, Hagiwara M, Nagatsu T, Hidaka H (1991) The newly synthesized selective $\mathrm{Ca}^{2+} /$ calmodulin dependent protein kinase II inhibitor KN-93 reduces dopamine contents in PC12h cells. J Neurochem 181:968-975.

Sun X, Zhao Y, Wolf ME (2005) Dopamine receptor stimulation modulates AMPA receptor synaptic insertion in prefrontal cortex neurons. J Neurosci 25:7342-7351.

Tomita S, Stein V, Stocker TJ, Nicoll RA, Bredt DS (2005) Bidirectional synaptic plasticity regulated by phosphorylation of stargazin-like TARPs. Neuron 45:269-277.

Tsui J, Malenka RC (2006) Substrate localization creates specificity in calcium/calmodulin-dependent protein kinase II signaling at synapses. J Biol Chem 281:13794-13804.

Turrigiano GG, Nelson SB (2004) Homeostatic plasticity in the developing nervous system. Nat Rev Neurosci 5:97-107.

Vanderschuren LJ, Everitt BJ (2004) Drug seeking becomes compulsive after prolonged cocaine self-administration. Science 305:1017-1019.

Vargas GA, von Zastrow M (2004) Identification of a novel endocytic recycling signal in the D1 dopamine receptor. J Biol Chem 279:37461-37469.

White FJ, Kalivas PW (1998) Neuroadaptations involved in amphetamine and cocaine addiction. Drug Alcohol Depend 51:141-153.

Wolf ME (1998) The role of excitatory amino acids in behavioral sensitization to psychomotor stimulants. Prog Neurobiol 54:679-720.

Wolf ME, Sun X, Mangiavacchi S, Chao SZ (2004) Psychomotor stimulants and neuronal plasticity. Neuropharmacol 47 [Suppl 1]:61-79.

Zhu JJ, Qin Y, Zhao M, Van Aelst L, Malinow R (2002) Ras and Rap control AMPA receptor trafficking during synaptic plasticity. Cell 110:443-455. 